\title{
Eco-mechanisms within economic evolution: Schumpeterian approach
}

\author{
Agnieszka Lipieta* (10) and Andrzej Malawski
}

\section{${ }^{*}$ Correspondence:}

alipieta@uek.krakow.pl Department of Mathematics, Cracow University of Economics, Rakowicka 27, 31-510 Cracow, Poland

\begin{abstract}
Supporting ecological innovations and economic activities which lead to environmental protection is one of the important challenges to decision-makers. The above is related to the problem of specification of mechanisms resulting in introducing ecological innovations to the economy. The original vision of the economic evolution determined by innovation was firstly presented by Joseph Schumpeter who identified essential innovative changes as well as indicated different mechanisms governing the economic evolution. The aim of the paper is to suggest a cohesive topological approach maintained in the stream of Schumpeter's thought, to study changes in the economy, which result in the elimination of at least one harmful commodity or technology from the market, by incorporating Hurwicz apparatus in a suitably modified competitive economy. Qualitative properties of mechanisms which can occur within the economic evolution are also analyzed.
\end{abstract}

Keywords: Eco-innovation, Eco-mechanism, Economic evolution

JEL: D41, D50, O31

\section{Introduction}

In the current paper prefix "eco" is used to distinguish among the phenomena usually analyzed in evolutionary economics those which have overall benefits for the environment, i.e., eco-innovations, eco-mechanisms, eco-changes, eco-activities, etc. Ecological innovation, in short eco-innovation, "is any innovation resulting in significant progress towards the goal of sustainable development, by reducing the impacts of our production modes on the environment, enhancing nature's resilience to environmental pressures, or achieving a more efficient and responsible use of natural resources" (European Commission 2009). In the interest of each community is supporting eco-innovations and ecoactivities, i.e., activities which lead to an environmental protection and improvement of the environment and the above should be the most important task and the challenge to decision-makers. In this context, ecological economic mechanisms, in short eco-mechanisms, i.e., economic mechanisms bringing changes beneficial for the environment, are worth to be studied. The concept of eco-innovation was widely explored (Arundel and Kemp 2009, Joller 2012; Rennings 2000; Carrillo-Hermosilla et al. 2010; Faucheux and 
Nicolaï 2011; Antonioli et al. 2016; Crespi et al. 2016; Leal-Millán et al 2017; Szutowski et al. 2017; Dewick et al. 2019).

Defining and analysis of the rules governing economic life were in the focus of interest of Joseph Schumpeter (1912, 1934, 1950, 1964). Schumpeter (1950) defined a mechanism, clarifying the structure of the process of the economic development called the creative destruction. The creative destruction, by Schumpeter, was the coexistence of two opposite processes: innovations resulting in the introduction of new commodities, new technologies and new organizational structures, etc., and processes of elimination of existing, outdated solutions. However, specification of mechanisms of economic evolution has not been presented by Schumpeter in a satisfactory way (Shionoya 2015; Lipieta and Malawski 2016).

The Schumpeter's ideas found many followers. Nelson and Winter (1982) initiated the neoschumpeterian research program as well as significantly developed the Schumpeterian ideas, among others, by, respecting the paradigm of the bounded rationality (see for instance Hayek 1945; Alchian 1950; Simon 1947, 1957) and criticism of the principles of the perfect rationality as they were not reflected in the economic life, focusing, opposite to the neoclassical and Keynesian conceptions, on the mesosphere of the economy as it was the area of occurrence of innovative processes as well as applying the strict methodology of mathematical modeling of economic development. Aghion and Howitt (1992, 1998), who laid down the beginning of the theory of endogenous economic growth, saw the source of economic development in the effectiveness of activities of the R\&D sector, but not in the accumulation of capital, as it was in case of the Solow's neoclassical theory of economic growth (Romer 2012).

Our analysis takes static as well as dynamic forms of the economy. Such approach is fundamentally different from the main stream of modern studying of the Schumpeterian evolution which includes two paths of economic theorizing, i.e., neo-Schumpeterian research program (Hanusch and Pyka 2007; Day 2007; Andersen 2009; Foster 2011; Freeman 1982; Malerba and Orsenigo 1995, 1997; Nelson 2016; Witt 2017) and Schumpeterian endogenous growth theory (Dosi et al. 2010; Assenza et al. 2015; Dawid et al. 2019; Almudi et al. 2019a, b). The difference can be seen in the mathematical setting based on the set-theoretical and topological apparatus which is borrowed from general equilibrium theory. The motivation for using the general equilibrium framework in our paper is clear-Schumpeter's vision on economic evolution was strongly inspired by Walrasian thinking (Hodgson 1993; Andersen 2009). However, it should be emphasized that the central idea of general equilibrium has been only a starting point for Schumpeter's study on economic development which runs far beyond equilibrium schemata (Malawski 2013, 2005, 2008; Malawski and Woerter 2006; Ciałowicz and Malawski 2011; Lipieta and Malawski 2016). On the one hand, the employment of such specific methodology maintains our research in the main stream of Schumpeter's thought, on the other hand gives an opportunity to avoid some strong mathematical assumptions (such as differentiability of utility functions) not realistic in the analysis of economic objects. However, above all, we aim at analysis and specification of various kinds of mechanisms that can occur or be implemented within the evolution of the economy with particular focus on eco-mechanisms. Some partial results on modeling mechanisms of economic change within which harmful commodities or technologies were reduced from agents' activities 
were presented in (Lipieta 2010, 2015). In difference to the above, we suggest a model of Schumpeterian economic evolution within which, at its every stage, eco-mechanisms can be implemented (Example 1, Theorems 1-3).

The economic mechanisms presented are formed in the conceptual apparatus of the Hurwicz theory (Hurwicz and Reiter 2006), while the economic transformation is modeled as an adjustment process (Hurwicz 1987). The Hurwicz mechanism design theory begun with the paper by Leonid (Hurwicz 1960). It aimed at formalizing institutions and economic processes to examine how they could achieve optimal outcomes (Hurwicz 1987). The above made the economic mechanisms in the sense of Hurwicz could be applied in many areas of economic theory. Later, in mechanism design theory the problems of incentives (Hurwicz 1972), uncertainty (Marschak and Radner 1971; Radner 1972) as well as the roles of the signals based on agents' private information (Mount and Reiter 1974) were taken into account. Economic mechanisms were broadly examined and widely disseminated by Eric Maskin (Maskin and Riley 1984; Dewatripont and Maskin 1995; Maskin et al. 2000) and Roger Myerson (1979, 1983, 1984). In the recent years the concept of Hurwicz economic mechanisms has been applied in a large number of fields such as health care (see for example Bonnevie et al. 2006), kidney exchange (see Roth et al. 2004), school choice (Abdulkadiroğlu and Sönmez 2003) or school matching (Abdulkadiroğlu et al. 2005) as well as many examples of strategy-proof and Pareto-efficient mechanisms resulting in specific goals have been constructed and analyzed (see, among others, Sönmez and Ünver 2011; Pycia and Ünver 2017).

The aim of mechanism design theory is to describe, analyze, compare and potentially regulate structures and procedures in order to achieve desired goals under given initial conditions, by the use of mathematical methods. The designing of an economic mechanism in the sense of Hurwicz starts from the determination of initial conditions, namely the so-called economic environment. The economic environment is a set or a sequence of variables and sets that determine individuals and firms as the economic agents. The Hurwicz economic mechanisms are the relational system (see for instance Adamowicz and Zbierski 1997) consisted of:

- a message space, i.e., a set or a sequence of all feasible signals (information) sent by economic agents; these signals are the result of agents' activities on the market and they can be noticed, recognized and analyzed by other economic agents,

- a message correspondence, which assigns to every environment, hence indirectly to economic entities, the signals (information) identified and analyzed by economic agents,

- an outcome function, which assigns to every message, the outcomes of activities of economic agents undertaken as a result of this message.

Hence, Hurwicz economic mechanism can be thought as a system of exchanging messages, which results in the agents' decisions concerning their activities on the markets. The use of the concept of Hurwicz mechanism enables us to establish rigorous theoretical basis to talk about moving towards sustainability through eco-innovation.

The paper consists of seven parts. In the second part, the economy in the form of the circular flow is modeled, the third part takes characterization of innovative 
changes. The fourth part is devoted to the mathematical model of the economic evolution, while in the fifth part various kinds of eco-mechanisms in the framework of the economic evolution are specified. The sixth part is devoted to discussion, the seven part concludes.

\section{The economy in the form of the circular flow}

Schumpeter distinguished two forms of economic life: the circular flow and the economic development (Schumpeter 1912, 1934, 1950, 1964), however, the relationship between these two forms has not been presented by Schumpeter in a satisfactory way (see Shionoya 2015; Lipieta and Malawski 2016). As it was emphasized (Schumpeter 1964; Lipieta, and Malawski 2016), the economy in the form of the circular flow due to Schumpeter's analogy reminds of the circulation of blood in a living organism. Thus, in the form of the circular flow, an economic system has the tendency to equilibrium state to determine prices and quantities of goods, the changes in activities of economic agents do not occur, or are so small that they do not influence current economic processes as well as operating of firms and consumers. The above lead us to the modeling the economy in the form of the circular flow by the use of the apparatus of theory of general equilibrium (Arrow and Debreu 1954; Mas-Colell et al. 1995).

At the beginning, we focus on the case when the activities of economic agents do not change within the given time interval. It is convenient to consider the countable number of inactive agents and a finite number of active agents, endogenously determined in the model. Such setting reflects the main premises of the creative destruction principle, namely that an unknown number of potential future producers "wait" for the proper time for themselves to enter the market or some of them are, or will be, eliminated from the economic life. Similarly, an unknown number of consumers may appear on the market in the future. First, the production sphere of an economy will be defined. Let

- $B=\left(b_{j}\right)_{j \in \mathbb{N}}$-be a countable set of heterogeneous producers,

- $y: B \ni b_{j} \rightarrow Y^{b_{j}} \subset \mathbb{R}^{\uparrow}$-be a correspondence of production sets, which to every producer $b_{j}$ assigns a non-empty production set $y\left(b_{j}\right)=Y^{b_{j}} \subset \mathbb{R}^{\complement}$ of the producer's feasible production plans as well as

$$
\exists n \in \mathbb{N} \forall j>n: y\left(b_{j}\right) \stackrel{\text { def }}{=}\{0\},
$$

- $p \in \mathbb{R}^{\AA}$ be a price vector.

Definition 1 The two-range relational system

$$
P_{q}=\left(B, \mathbb{R}^{\ell} ; y, p\right)
$$

is called the quasi-production system. If, additionally, for every $b \in B$

$$
\eta^{b}(p) \stackrel{\text { def }}{=}\left\{y^{b *} \in Y^{b}: p \circ y^{b *}=\max \left\{p \circ y^{b}: y^{b} \in Y^{b}\right\}\right\} \neq \emptyset,
$$

then quasi-production system $P_{q}$ is called the production system and denoted by $P$. 
The producer $b_{j}$ for which $y\left(b_{j}\right)=\{0\}$ is called the inactive producer while the producer for which $y\left(b_{j}\right) \neq\{0\}$ is called the active one. The elements of set $\eta^{b}(p)$ are called the optimal plans of producer $b$. Let us recall (Lipieta and Malawski 2016) that, in the spirit of the assumption of bounded rationality (Simon 1955), in the quasi-production system, the aims of producers are not specified, while in the production system, producers maximize profits at given prices and technologies.

Similarly, a quasi-consumption system is defined. Let

- $A=\left(a_{i}\right)_{i \in \mathbb{N}}$ be a countable set of consumers,

- $\Xi \subset \mathbb{R}^{\downarrow} \times \mathbb{R}^{\downarrow}$ be the family of all preference relations in $\mathbb{R}^{\downarrow}$,

- $\chi: A \ni a_{i} \rightarrow \chi\left(a_{i}\right)=X^{a_{i}} \subset \mathbb{R}^{\mathfrak{I}}$ be a correspondence of consumption sets which to every consumer $a_{i}$ assigns a non-empty consumption set $\chi\left(a_{i}\right)=X^{a_{i}}$ being a subset of commodity space $\mathbb{R}^{\ddagger}$ and representing the consumer's feasible consumption plans; moreover

$$
\exists m \in \mathbb{N} \forall i>m: \chi\left(a_{i}\right) \stackrel{\text { def }}{=}\{0\},
$$

- $\epsilon: A \ni a_{i} \rightarrow \epsilon\left(a_{i}\right)=\omega^{a_{i}} \in \chi\left(a_{i}\right)$ be an initial endowment mapping,

- $\varepsilon \subset A \times\left(\mathbb{R}^{\downarrow} \times \mathbb{R}^{\downarrow}\right)$ be a correspondence, which to every consumer $a \in A$ assigns a preference relation $\preccurlyeq_{a}$ from set $\Xi$ restricted to set $\chi(a) \times \chi(a)$,

- $p \in \mathbb{R}^{\perp}$ be a price vector.

Definition 2 The three-range relational system

$$
C_{q}=\left(A, \mathbb{R}^{\ell}, \Xi ; \chi, \epsilon, \varepsilon, p\right)
$$

is called the quasi-consumption system. If, for every $a \in A$,

$$
\begin{aligned}
& \beta^{a}(p)=\{x \in \chi(a): p \circ x \leq p \circ \epsilon(a)\} \neq \emptyset, \\
& \varphi^{a}(p)=\left\{x^{a *} \in \beta^{a}(p): \forall x^{a} \in \beta^{a}(p) x^{a} \preccurlyeq_{a} x^{a *}, \preccurlyeq_{a} \in \Xi\right\} \neq \emptyset,
\end{aligned}
$$

then the quasi-consumption system $C_{q}$ is called the consumption system and denoted by $C$.

Similarly to the case of producers, the consumer $a_{i}$ for which $\chi\left(a_{i}\right)=\{0\}$ is called the inactive consumer while the consumer for which $\chi\left(a_{i}\right) \neq\{0\}$ is called the active one. In the quasi-consumption systems, the upper bound for preference relation on a consumer's budget set does not have to exist. However, according to the assumption of perfect rationality, every consumer realizes one of his optimal plans of action if any exists. Now, we can assume the following definition, which is a slight modification of the original 
Arrow and Debreu economy (compare to Arrow and Debreu 1954; Debreu 1959; Mas-

Colell et al. 1995; Lipieta 2010):

$$
\text { Let } \tilde{A}=\left\{a_{1}, \ldots, a_{m}\right\} \text { and } \widetilde{B}=\left\{b_{1}, \ldots, b_{n}\right\} \text {. }
$$

Definition 3 The relational system

$$
\varepsilon_{q}=\left(\mathbb{R}^{l}, P_{q}, C_{q}, \theta, \omega\right),
$$

where:

- $P_{q}=\left(B, \mathbb{R}^{\uparrow} ; y, p\right)$ is the quasi-production system,

- The mapping $\theta: A \times B \rightarrow[0,1]$ satisfies:

$$
\theta\left(a_{i}, b_{j}\right)=0 \text { if } i>m \text { or } j>n, \forall b \in \tilde{B} \sum_{a \in \tilde{A}} \theta(a, b)=1,
$$

- $C_{q}=\left(A, \mathbb{R}^{\downarrow}, \Xi ; \chi, \epsilon, \varepsilon, p\right)$ is the quasi-consumption system,

- $\epsilon\left(a_{i}\right) \in \mathbb{R}^{\beth}$ for $i \in \mathbb{N}, \epsilon\left(a_{i}\right) \stackrel{\text { def }}{=} 0 \in \mathbb{R}^{\complement}$ for $i>m$ as well as $\sum_{a \in A} \omega^{a}=\omega$

is called the private ownership economy with almost all inactive agents, shortly the economy.

If $P_{q}$ is the production system $\left(P_{q}=P\right)$ and $C_{q}$ is the consumption system $\left(C_{q}=C\right)$, then private ownership economy with almost all inactive agents $\epsilon_{q}$ will be denoted by $\epsilon=\left(\mathbb{R}^{\beth}, P, C, \theta, \omega\right)$ or in short $\epsilon_{q}=\epsilon$.

The private ownership economy with almost all inactive agents operates as follows.

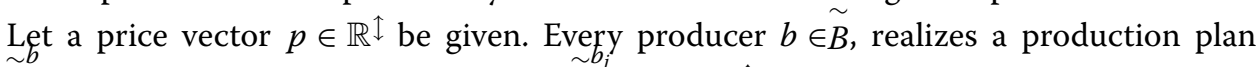
$\tilde{y}^{b} \in y(b)$. For $j>n$, it is assumed that $\tilde{y}^{b_{j}}=0 \in \mathbb{R}^{\downarrow}$. It means that, for $j>n$, producer $b_{j}$ is not active in the economy at the given moment $\left(b_{j} \in B \backslash \widetilde{B}\right)$. The profit of each active producer $b(b \in \widetilde{B})$ by realization of the plan $\tilde{y}^{b}$, is divided among all active consumers according to function $\theta$. Hence, the expenditure (wealth) of every consumer $a$ is equal

$$
w(a)=p \circ \epsilon(a)+\sum_{b \in \tilde{B}} \theta(a, b) \cdot p \circ \tilde{y}^{b}
$$

and, consequently, the budget set of every active consumer $a$ at price system $p$ is of the form:

$$
\beta^{a}(p)=\{x \in \chi(a): p \circ x \leq w(a)\} .
$$

If $\beta^{a}(p) \neq \varnothing$ and $\varphi^{a}(p) \neq \varnothing$, then active consumer $a$ chooses his consumption plan $x^{a *} \in \varphi^{a}(p) \subset \chi(a)$ maximizing $\underset{\sim}{\sim}$ is preference on budget set $\beta^{a}(p)$. If $\beta^{a}(p) \neq \varnothing$ and $\varphi^{a}(p)=\varnothing$, then a consumer $a \in \tilde{A}$ chooses a consumption plan $\tilde{x}_{\sim a}^{a} \in \beta^{a}(p)$, due to his own criterion. If $\beta^{a}(p)=\varnothing$, then we assume that $\tilde{x}^{a}=0 \in \mathbb{R}^{\downarrow}$. To every inactive consumer (for $i>m$ ) plan $\tilde{\sim}^{a_{i}}=0 \in \mathbb{R}^{\downarrow}$ is assigned. The allocation $\left(\left(x^{a}\right)_{a \in A},\left(y^{b}\right)_{b \in B}\right)$, where $\left(x^{a}\right)_{a \in A} \stackrel{\text { def }}{=}\left(x^{a_{1}}, \ldots, x^{a_{m}}, 0,0, \ldots\right)$ and $\left(y^{b}\right)_{b \in B} \stackrel{\text { def }}{=}\left(y^{b_{1}}, \ldots, y^{b_{n}}, 0,0, \ldots\right)$, is called feasible, if 


$$
\sum_{a \in A} x^{a}-\sum_{b \in B} y^{b}=\sum_{a \in A} \omega^{a}
$$

If $\epsilon_{q}=\epsilon$, then for every producer $b$ there exists a plan $y^{b *} \in \eta^{b}(p)$ and for every consumer $a$-a plan $x^{a *} \in \varphi^{a}(p)$. If allocation $\left(\left(x^{a *}\right)_{a \in A},\left(y^{b *}\right)_{b \in B}\right)$, in which $y^{b *} \in \eta^{b}(p)$ and $x^{a *} \in \varphi^{a}(p)$ for every $a \in A$ and $b \in B$, is feasible, then the sequence

$$
\left(\left(x^{a *}\right)_{a \in A},\left(y^{b *}\right)_{b \in B}, p\right)
$$

where $\left(x^{a *}\right)_{a \in A} \stackrel{\text { def }}{=}\left(x^{a_{1} *}, \ldots, x^{a_{m} *}, 0,0, \ldots\right)$ and $\left(y^{b *}\right)_{b \in B} \stackrel{\text { def }}{=}\left(y^{b_{1} *}, \ldots, y^{b_{n} *}, 0,0, \ldots\right)$, is called the state of equilibrium in economy $\epsilon$.

Time is considered as a discrete variable. In particular $t=0$ means an initial point of a process analyzed whereas every number $t \in\{1,2, \ldots\}$ is identified with time interval $[t-1, t)$ on which the activities (i.e., plans of action) of producers and consumers are not changed. The lengths (ranges) of times intervals do not have to be equal. Saying "at time $t$ ", we mean "at time interval $[t-1, t)$ ". Such approach enables us to observe, compare and measure changes and their results in the economy under study.

Let $t, t^{\prime} \in\{1,2, \ldots\}, \quad t<t^{\prime}$. Assume that quasi-production systems $P_{q}(t)=\left(B, \mathbb{R}^{\uparrow_{t}} ; y_{t}, p(t)\right)$ and $P_{q}\left(t^{\prime}\right)=\left(B^{\prime}, \mathbb{R}^{\uparrow_{t^{\prime}}} ; y_{t^{\prime}}, p\left(t^{\prime}\right)\right)$ are mathematical equivalents of production sphere of an economy at time $t$ and $t^{\prime}$, respectively. The system $P_{q}\left(t^{\prime}\right)$ is called the transformation of system $P_{q}(t)$, which is noted by $P_{q}(t) \subset P_{q}\left(t^{\prime}\right)$. Keeping in mind the assumptions of countable number of producers, we assume that if $P_{q}(t) \subset P_{q}\left(t^{\prime}\right)$, then $B=B^{\prime}$. Without loss of generality, we can also assume that $\uparrow_{t} \leq \uparrow_{t^{\prime}}$.

Definition 4 Quasi-production system $P_{q}\left(t^{\prime}\right)$ is called the imitative transformation of quasi-production system $P_{q}(t)$, in short $P_{q}(t) \subset_{\text {imt }} P_{q}\left(t^{\prime}\right)$, if

1. $\uparrow_{t}=\uparrow_{t^{\prime}}$,

2. $\forall b \in B: Y^{b}\left(t^{\prime}\right) \subset \bigcup_{b \in B} Y^{b}(t)$.

If $P_{q}(t) \subset_{\text {imt }} P_{q}\left(t^{\prime}\right)$ and additionally,

3. $\forall b \in B: Y^{b}(t) \subset Y^{b}\left(t^{\prime}\right)$,

4. $\forall b \in B \forall y^{b}(t) \in Y^{b}(t) \exists y^{b}\left(t^{\prime}\right) \in Y^{b}\left(t^{\prime}\right): p(t) \circ y^{b}(t) \leq p\left(t^{\prime}\right) \circ y^{b}\left(t^{\prime}\right)$,

then quasi-production system $P_{q}\left(t^{\prime}\right)$ is called the cumulative transformation of quasiproduction system $P_{q}(t)$, in short $P_{q}(t) \subset_{c t} P_{q}\left(t^{\prime}\right)$.

In an imitative transformation of a given quasi-production system, there appear neither new firms nor new commodities (conditions 1 and 2) as well as there is no new technologies at time $t^{\prime}$ with respect to time $t$ (condition 2). In a cumulative transformation of a quasi-production system, additionally, the commodities and technologies used at time $t$ can be used at time $t^{\prime}$ (condition 3) as well as economic positions of producers at time $t^{\prime}$ (see also Lipieta and Malawski 2016) are not worse than at time $t$ (condition 4). Precisely speaking, condition 4 means that adequate profits in system 
$P_{q}\left(t^{\prime}\right)$ are not less than in system $P_{q}(t)$. Let us also notice that, if $P_{q}(t) \subset_{c t} P_{q}\left(t^{\prime}\right)$, then $P_{q}(t) \subset_{i m t} P_{q}\left(t^{\prime}\right)$.

Suppose that quasi-consumption systems $C_{q}(t)=\left(A, \mathbb{R}^{I_{t}}, \Xi_{t} ; \chi_{t}, \epsilon_{t}, \varepsilon_{t}, p(t)\right)$ and $C_{q}\left(t^{\prime}\right)=\left(A^{\prime}, \mathbb{R}^{\uparrow_{t^{\prime}}}, \Xi_{t^{\prime}} ; \chi_{t^{\prime}}, \epsilon_{t^{\prime}}, \varepsilon_{t^{\prime}}, p\left(t^{\prime}\right)\right)$ are mathematical models of consumption sphere at time $t$ and $t^{\prime}$, respectively. System $C_{q}\left(t^{\prime}\right)$ is called the transformation of system $C_{q}(t)$, which is noted by $C_{q}(t) \subset C_{q}\left(t^{\prime}\right)$. Similarly, as in case of a production sector, it is assumed that if $C_{q}(t) \subset C_{q}\left(t^{\prime}\right)$, then $A=A^{\prime}$ and $\uparrow_{t} \leq \uparrow_{t^{\prime}}$.

Definition 5 Quasi-consumption system $C_{q}\left(t^{\prime}\right)$ is said to be the imitative transformation of quasi-consumption system $C_{q}(t)$, in short denoted $C_{q}(t) \subset_{i m t} C_{q}\left(t^{\prime}\right)$, if

1. $\uparrow_{t}=\uparrow_{t^{\prime}}$,

2. $\forall a \in A: X^{a}\left(t^{\prime}\right) \subset \bigcup_{a \in A} X^{a}(t)$.

If $C_{q}(t) \subset_{i m t} C_{q}\left(t^{\prime}\right)$ and additionally,

3. $\forall a \in A: X^{a}(t) \subset X^{a}\left(t^{\prime}\right)$,

4. $\forall a \in A: \epsilon_{t}(a) \leq \epsilon_{t^{\prime}}(a)$

5. $\forall a \in A: \varepsilon_{t}(a) \subset \varepsilon_{t^{\prime}}(a)$,

6. $\forall a \in A \forall x^{a} \in \beta_{t}^{a}(p) \exists x^{\prime a} \in \beta_{t^{\prime}}^{a}\left(p^{\prime}\right): x^{a} \preccurlyeq_{a}^{t^{\prime}} x^{\prime a}$,

then quasi-consumption system $C_{q}\left(t^{\prime}\right)$ is called the cumulative transformation of quasiconsumption system $C_{q}(t)$, in short $C_{q}(t) \subset_{c t} C_{q}\left(t^{\prime}\right)$.

In an imitative transformation of a given quasi-consumption system, neither new consumers nor new commodities appear (conditions 1 and 2) at time $t^{\prime}$ with respect to time $t$. In a cumulative transformation of a given quasi-consumption system, additionally, consumers' commodity bundles demanded at time $t$ are still wished by consumers at time $t^{\prime}$ (condition 3) as well as initial endowments are non-decreasing (condition 4). If $\varepsilon_{t}(a)=\varepsilon_{t \prime}(a)$, then the preference relation of consumer $a$ at time $t^{\prime}$ is the same as his preference relation at time $t$; if $\varepsilon_{t}(a) \subsetneq \varepsilon_{t^{\prime}}(a)$, then the preference relation of consumer $a$ at time $t^{\prime}$ is the extension of his preference relation from time $t$ (condition 5). Finally, consumers' commodity bundles that can be realized at time $t^{\prime}$ are preferred not less than consumption plans feasible to realization at time $t$ (condition 6). On the basis of the above, it can be said that if $C_{q}(t) \subset_{c t} C_{q}\left(t^{\prime}\right)$, then the economic positions of consumers in system $C_{q}\left(t^{\prime}\right)$ are not worse than in system $C_{q}(t)$ (Lipieta and Malawski 2016). It is obvious that, if $C_{q}(t) \subset_{c t} C_{q}\left(t^{\prime}\right)$, then $C_{q}(t) \subset_{i m t} C_{q}\left(t^{\prime}\right)$.

Now let us consider economies $\epsilon_{q}(t)=\left(\mathbb{R}^{\downarrow_{t}}, P_{q}(t), C_{q}(t), \theta_{t}, \omega(t)\right)$ and $\epsilon_{q}\left(t^{\prime}\right)=\left(\mathbb{R}^{I_{t^{\prime}}}, P_{q}\left(t^{\prime}\right), C_{q}\left(t^{\prime}\right), \theta_{t^{\prime}}, \omega\left(t^{\prime}\right)\right)$ at time $t$ and $t^{\prime}$, respectively. As previously, economy $\epsilon_{q}\left(t^{\prime}\right)$ is called the transformation of economy $\epsilon_{q}(t)$ which is noted by $\epsilon_{q}(t) \subset \epsilon_{q}\left(t^{\prime}\right)$. Now the following definition can be formulated:

Definition 6 Economy $\epsilon_{q}\left(t^{\prime}\right)$ is said to be the imitative transformation of economy $\epsilon_{q}(t)$, in short $\epsilon_{q}(t) \subset_{i m t} \epsilon_{q}\left(t^{\prime}\right)$, if $P_{q}(t) \subset_{i m t} P_{q}\left(t^{\prime}\right)$ and $C_{q}(t) \subset_{i m t} C_{q}\left(t^{\prime}\right)$. Economy $\epsilon_{q}\left(t^{\prime}\right)$ is said to be the cumulative transformation of economy $\epsilon_{q}(t)$, in short $\epsilon_{q}(t) \subset_{c t} \epsilon_{q}\left(t^{\prime}\right)$, if $P_{q}(t) \subset_{c t} P_{q}\left(t^{\prime}\right)$ and $C_{q}(t) \subset_{c t} C_{q}\left(t^{\prime}\right)$. 
If $\epsilon_{q}(t) \subset_{c t} \epsilon_{q}\left(t^{\prime}\right)$, then consumers and producers are not worse off at time $t^{\prime}$ than at time $t$. If the economy is in equilibrium, then economic agents can realize their optimal plans of action by given prices and technologies. These plans form the feasible allocation. Under such conditions, the economic agents do not have motivation to change their activities on the market unless innovators operate in the economy or some other (external or internal) strengths force any changes in agents' activities. On the basis of the presented definitions, it is clear that an economy in the form of the circular flow can be modeled by either the private ownership economy or by a sequence of such economies in which every next economy is the cumulative transformation of the previous one. The problems of existence or keeping equilibrium during the transformation of the economy are complex. Some examples of mechanisms leading to equilibrium in the economy or in its transformations are presented in parts 4 and 5 of the current paper.

The specification of the transformations at time $t^{\prime}$ is determined on the basis of the properties of the economy at time $t$. However, it is easy to notice that features "being the imitative transformation" or "being the cumulative transformation" have properties transitivity, i.e., for $t, t^{\prime}, t^{\prime \prime} \in\{1,2, \ldots\}, t<t^{\prime}$ and $t^{\prime}<t^{\prime \prime}$, the following is true:

1. If $\varepsilon_{q}(t) \subset_{i m t} \varepsilon_{q}\left(t^{\prime}\right)$ and $\varepsilon_{q}\left(t^{\prime}\right) \subset_{i m t} \varepsilon_{q}\left(t^{\prime \prime}\right)$, then $\varepsilon_{q}(t) \subset_{i m t} \varepsilon_{q}\left(t^{\prime \prime}\right)$,

2. If $\varepsilon_{q}(t) \subset_{c t} \varepsilon_{q}\left(t^{\prime}\right)$ and $\varepsilon_{q}\left(t^{\prime}\right) \subset_{c t} \varepsilon_{q}\left(t^{\prime \prime}\right)$, then $\varepsilon_{q}(t) \subset_{c t} \varepsilon_{q}\left(t^{\prime \prime}\right)$.

\section{Innovative changes in the economy}

Let us recall that innovations or innovative changes are new products or new technologies introduced by producers (Schumpeter 1912), while eco-innovations are the innovations which reduce the impact of consumers' and producers' activities on the environment (compare to European Commission 2009; Szutowski et al. 2017). Eco-innovations involve, among others, eliminating or reducing the use of harmful commodities from the market and detrimental technologies from agents' activities.

To model innovative changes that can be observable in the economy, we have to formulate conditions that enable us to recognize that innovations appear at time $t^{\prime}$ compared to time $t, 1 \leq t<t^{\prime}$. Following Schumpeter's ideas, we admit that the creative natures of entrepreneurs make they generate new products or new technologies. Instead of aiming at the profit maximization, a producer may undertake some innovative activities and realize a production plan which offers the possibility of future profits. Due to the above, a potential innovation is endogenous in the model. The producers who introduce innovations are called the innovators. An innovator may achieve the increase in the profit or not. Eco-innovation in the presented approach is a new product or a new technology which is friendly for the environment. Thus, if a harmful commodity or a detrimental technology is removed from economic processes, then such technological change will be eco-innovation.

As earlier, $t, t^{\prime} \in\{1,2, \ldots\}, t<t^{\prime}$. Let us consider quasi-production systems $P_{q}(t)$ and $P_{q}\left(t^{\prime}\right)$, where $P_{q}(t) \subset P_{q}\left(t^{\prime}\right)$. If some innovations are visible at time $t^{\prime}$ compared to time 
$t$, then it is said that quasi-production system $P_{q}^{\prime}$ is the innovative transformation of the quasi-production system $P_{q}$ (compare to Lipieta 2018). More formally, we suggest:

Definition 7 Quasi-production system $P_{q}\left(t^{\prime}\right)$ is called the innovative transformation of quasi-production system $P_{q}(t)$, in short $P_{q}(t) \subset_{i t} P_{q}\left(t^{\prime}\right)$, if,

$$
\begin{aligned}
& \text { 1. } l_{\tau}<l_{\tau^{\prime}} \Rightarrow \exists b_{0} \in B \exists y^{b_{0}}\left(t^{\prime}\right) \in Y^{b_{0}}\left(t^{\prime}\right) \forall b \in B: y^{b_{0}}\left(t^{\prime}\right) \notin \bigcup_{b \in B} Y^{b}(t), \\
& \text { 2. } l_{\tau}<l_{\tau^{\prime}} \Rightarrow \exists b_{0} \in B \exists y^{b_{0}}\left(t^{\prime}\right) \in Y^{b_{0}}\left(t^{\prime}\right) \forall b \in B: y^{b_{0}}\left(t^{\prime}\right) \notin \bigcup_{b \in B}\left(Y^{b}(t) \times\{0\} \times \cdots \times\{0\}\right) \subset \mathbb{R}^{t^{\prime}} .
\end{aligned}
$$

Let us notice that if $P_{q}(t) \subset_{i t} P_{q}\left(t^{\prime}\right)$ and $\uparrow_{t}=\uparrow_{t^{\prime}}$, then new technologies are the only innovations at time $t^{\prime}$ with respect to time $t$ (condition 1). If $P_{q}(t) \subset_{i t} P_{q}\left(t^{\prime}\right)$ and $\uparrow_{t}<\uparrow_{t^{\prime}}$, then a new commodity is introduced as well as at least one innovator introduces new technology into the production sphere (condition 2) at time $t^{\prime}$ with respect to time $t$. The producer satisfying condition 1 or 2 is the innovator. If producer is the innovator, then the vectors $y^{b_{0}}\left(t^{\prime}\right)$ satisfying condition (2) by Definition 7 are called (his) innovative plans. If an innovation described by the vector $y^{b_{0}}\left(t^{\prime}\right)$ is an ecoinnovation, then innovator $b_{0}$ is called eco-innovator.

We assume that, if $P_{q}(t) \subset_{i t} P_{q}\left(t^{\prime}\right)$, then at time $t^{\prime}$ at least one innovator realizes one of his innovative plans. The above is coherent with Schumpeter's theory. If $P_{q}(t) \subset_{i t} P_{q}\left(t^{\prime}\right)$ and additionally

$$
\begin{aligned}
& \ell_{t}=\ell_{t^{\prime}} \Rightarrow \exists b_{o} \in B \forall y^{b}(t) \in y_{t}(b) \exists y^{b_{0}}\left(t^{\prime}\right) \in Y^{b_{0}}\left(t^{\prime}\right) \backslash \bigcup_{b \in B} y_{t}(b): \\
& \text { or } p(t) \circ y^{b}(t)<p\left(t^{\prime}\right) \circ y^{b_{0}}\left(t^{\prime}\right), \\
& \text { - } \ell_{t}<\ell_{t^{\prime}} \Rightarrow \exists b_{o} \in B \forall y^{b}(t) \in y_{t}(b) \exists y^{b_{0}}\left(t^{\prime}\right) \in Y^{b_{0}}\left(t^{\prime}\right) \backslash\left(\bigcup_{b \in B}\left(Y^{b}(t) \times\{0\} \times \ldots \times\{0\}\right)\right): \\
& p(t) \circ y^{b}(t)<p\left(t^{\prime}\right) \circ y^{b_{0}}\left(t^{\prime}\right),
\end{aligned}
$$

then innovative plan $y^{b_{0}}\left(t^{\prime}\right)$ gives a higher profit at price vector $p\left(t^{\prime}\right)$ to innovator $b_{0}$ than any plan $y^{b_{0}}(t)$ at price vector $p(t)$. In that case the economic position of the innovator satisfying one of the above conditions, is better in system $P_{q}\left(t^{\prime}\right)$ than in system $P_{q}(t)$. If innovative changes are observable in the production sector at time $t^{\prime}$ with respect to time $t$, then the economy is not in the form of the circular flow and the economic development has already been started. Let $A=A^{\prime}, B=B^{\prime}, t<t^{\prime}, \uparrow_{t} \leq \uparrow_{t^{\prime}}$ and $\epsilon_{q}(t) \subset \epsilon_{q}\left(t^{\prime}\right)$. Now the following is defined:

Definition 8 Economy $\epsilon_{q}\left(t^{\prime}\right)$ is said to be the innovative transformation of economy $\epsilon_{q}(t)$, in short $\epsilon_{q}(t) \subset_{i t} \epsilon_{q}\left(t^{\prime}\right)$, if $P_{q}(t) \subset_{i t} P_{q}\left(t^{\prime}\right)$. Economy $\epsilon_{q}\left(t^{\prime}\right)$ is said to be the regressive transformation of economy $\epsilon_{q}(t)$, in short $\epsilon_{q}(t) \subset_{r t} \epsilon_{q}\left(t^{\prime}\right)$, if economy $\epsilon_{q}\left(t^{\prime}\right)$ is neither the innovative nor the cumulative transformation of economy $\epsilon_{q}(t)$.

If $\epsilon_{q}(t) \subset \epsilon_{q}\left(t^{\prime}\right)$ and $\epsilon_{q}\left(t^{\prime}\right)$ is not the innovative transformation of economy $\epsilon_{q}(t)$, then $P_{q}(t) \subset_{\text {imt }} P_{q}\left(t^{\prime}\right)$. In that case 
- if $P_{q}(t) \subset_{c t} P_{q}\left(t^{\prime}\right)$ and $C_{q}(t) \subset_{c t} C_{q}\left(t^{\prime}\right)$, then $\epsilon_{q}(t) \subset_{c t} \epsilon_{q}\left(t^{\prime}\right)$.

- if system $C_{q}\left(t^{\prime}\right)$ is not the cumulative transformation of system $C_{q}(t)$ or $P_{q}\left(t^{\prime}\right)$ is not the cumulative transformation of $P_{q}(t)$, then $\epsilon_{q}(t) \subset_{r t} \epsilon_{q}\left(t^{\prime}\right)$.

The innovative, cumulative and regressive transformations do not form an entire list of all possible transformations. On the basis of Schumpeter's theory, we can distinguish the creative destructive transformation in the set of innovative transformations as well as the imitative transformation in the set of regressive transformations. Let $\tilde{t}, \widehat{t} \in\left\{t, \ldots, t^{\prime}\right\}$. On the basis of Schumpeter's theory we put the following.

\section{Remark 1}

1. If, for every $\tilde{t}, \epsilon_{q}(\tilde{t}) \subset_{c t} \epsilon_{q}(\tilde{t}+1)$, then the economy is in the form of the circular flow in in the period from $t$ to $t^{\prime}$.

2. If $\epsilon_{q}(t) \subset_{i t} \epsilon_{q}\left(t^{\prime}\right)$, then the economy is in the form of the economic development in the period from $t$ to $t^{\prime}$.

3. If, in the period from $t$ to $t^{\prime}$, the economy is neither in the circular flow nor in the economic development, then we say that the economy is in regression.

The properties of various kinds of transformations are summarized in Table 1.

On the basis of the previous considerations, it is seen that nature of economic processes is quite complex because their properties also depend on the duration of a period analyzed. For every $t$, the economy at time $t$ is in the form of the circular flow. However, if, at every $\tilde{t} \in\left\{t, \ldots, t^{\prime}\right\}, \epsilon_{q}(\tilde{t}) \subset_{i m t} \epsilon_{q}(\tilde{t}+1)$ and for at least one $\tilde{t}, \epsilon_{q}(\tilde{t}+1)$ is not the cumulative transformation of economy $\epsilon_{q}(\tilde{t})$, then in the period from $t$ to $t^{\prime}$ as a whole the economy is neither in the circular flow nor in the economic development. The existence of the economy in the form other than those distinguished by Schumpeter is the consequence of the structure of the model. If at least one innovation can be recognized at time $t^{\prime}$ in comparison to time $t, t^{\prime}>t$, then the economy is in the form of the economic development in the period from $t$ to $t^{\prime}$. Thus, within a sufficiently long period, only the economic development or the circular flow is distinguished in the model under study, which is coherent with Schumpeter's theory.

\section{Evolution of the economy as the adjustment process}

Let $\tau \in\{1,2, \ldots\}$.The evolution of an economy on interval $[0, \tau]$ can be viewed as such an adjustment process (see Hurwicz 1987) that components of the environment form an economy with almost all inactive agents. The moment of time $t=0$ is a collusive, starting point of the given process, the moment $\tau$ means its ending point. If $\tau>2$, then the number $t \in\{2, \ldots, \tau-1\}$ means an intermediate point of time.

The definitions presented below are borrowed from the study by Hurwicz (1987) and adapted to the economy with the countable number of agents. Let countable set $K$ denote the set of economic agents. All characteristics, determining an individual as the $k$ th agent $(k \in K)$ in the given economic process, form the so-called economic environment of that 
Table 1 Summary of properties of transformation of the economic structures presented

\begin{tabular}{|c|c|c|}
\hline Kind of system & Kind of transformation & Properties of transformation \\
\hline Quasi-production system & Innovative & $\begin{array}{l}\text { At least one production plan, innovative in period } t^{\prime} \text { with } \\
\text { regard to period } t \text {, is realized in period } t^{\prime}\end{array}$ \\
\hline Quasi-production system & Imitative & $\begin{array}{l}\text { All production plan feasible to realization in period } t^{\prime} \text { were } \\
\text { feasible to realization in period } t \text {, which means that there } \\
\text { is no innovation in period } t^{\prime} \text { with regard to period } t\end{array}$ \\
\hline Quasi-production system & Cumulative & $\begin{array}{l}\text { (1) All production plans feasible to realization in period } t^{\prime} \\
\text { were feasible to realization in period } t \text {, which means that } \\
\text { there is no innovation in period } t^{\prime} \text { with regard to period } \\
t,(2) \text { every producer can realize in period } t^{\prime} \text { every his } \\
\text { production plan feasible to realization in period } t,(3) \text { the } \\
\text { economic position of every producer in period } t^{\prime} \text { is not } \\
\text { worse than in it was period } t\end{array}$ \\
\hline Quasi-consumption system & Imitative & $\begin{array}{l}\text { (1) There is no innovation on the market, (2) all consump- } \\
\text { tion plans feasible to realization in period } t^{\prime} \text { were feasible } \\
\text { to realization in period } t\end{array}$ \\
\hline Quasi-consumption system & Cumulative & $\begin{array}{l}\text { (1) There is no innovation on the market, }(2) \text { all consump- } \\
\text { tion plans feasible to realization in period } t^{\prime} \text { were feasible } \\
\text { to realization in period } t \text {, (3) every consumer can realize } \\
\text { in period } t^{\prime} \text { every his consumption plan feasible to } \\
\text { realization in period } t \text {, (4) the economic position of every } \\
\text { consumer in period } t^{\prime} \text { is not worse than it was in period } t\end{array}$ \\
\hline Economy & Innovative & $\begin{array}{l}\text { At least one production plan, innovative in period } t^{\prime} \text { with } \\
\text { regard to period } t \text {, is realized in period } t^{\prime}\end{array}$ \\
\hline Economy & Imitative & $\begin{array}{l}\text { Every agent's plan feasible to realization in period } t^{\prime} \text { were } \\
\text { feasible to realization in period } t \text {, which means that there } \\
\text { is no innovation in period } t^{\prime} \text { with regard to period } t\end{array}$ \\
\hline Economy & Cumulative & $\begin{array}{l}\text { (1) Every agent's plan feasible to realization in period } t^{\prime} \\
\text { were feasible to realization in period } t \text {, which means that } \\
\text { there is no innovation in period } t^{\prime} \text { with regard to period } \\
t,(2) \text { every agent can realize in period } t^{\prime} \text { every his plan of } \\
\text { action feasible to realization in period } t \text {, (3) the economic } \\
\text { position of every agent in period } t^{\prime} \text { is not worse than it } \\
\text { was in period } t\end{array}$ \\
\hline Economy & Regressive & $\begin{array}{l}\text { (1) Every agents' plan feasible to realization in period } t^{\prime} \\
\text { were feasible to realization in period } t \text {, which means that } \\
\text { there is no innovation in period } t^{\prime} \text { with regard to period } \\
t,(2) \text { at least one agent cannot realize in period } t^{\prime} \text { one of } \\
\text { his plan of action feasible to realization in period } t \text { or the } \\
\text { economic position of at least one agent in period } t^{\prime} \text { is } \\
\text { worse than it was in period } t\end{array}$ \\
\hline
\end{tabular}

agent. The economic environment of agent $k$ at time $t$ is denoted by $e^{k}(t)$. The symbol $E^{k}(t)$ stands for the set of all feasible economic environments of agent $k$ at time $t$. The set

$$
E_{t} \stackrel{\text { def }}{=} E^{k_{1}}(t) \times E^{k_{2}}(t) \times \ldots
$$

is called the set of economic environments at time $t$, vector

$$
e_{t}=\left(e^{k_{1}}(t), e^{k_{2}}(t), \ldots\right) \in E_{t}
$$

is called the economic environment at time $t$. Economic agents consciously or unconsciously send some messages to other agents. The set of messages to be used on the market by agent $k$ at time $t$ is denoted by $M^{k}(t)$, while its elements (messages) by $m^{k}(t)$. The vector 


$$
m_{t} \stackrel{\text { def }}{=}\left(m^{k_{1}}(t), m^{k_{2}}(t), \ldots\right) \in M_{t} \stackrel{\text { def }}{=} M^{k_{1}}(t) \times M^{k_{2}}(t) \times \ldots,
$$

where for every $k \in K, m^{k}(t) \in M^{k}(t)$, is called the message at time $t$. The process of exchanging messages may be represented by a system of equations of the form:

$$
m^{k}(t+1) \stackrel{\text { def }}{=} f_{t}^{k}\left(m_{t}, e_{t}\right), t=1, \ldots, \tau-1 ; k \in K
$$

$\tau \in\{1,2, \ldots\}$, where for every $k \in K$, the function

$$
f_{t}^{k}: M_{t} \times E_{t} \rightarrow M^{k}(t+1)
$$

is response function of the agent $k$ at time $t$. The function

$$
f_{t}=\left(f_{t}^{k_{1}}, f_{t}^{k_{2}}, \ldots\right): M_{t} \times E_{t} \rightarrow M_{t+1}
$$

is the response function at time $t(t=1, \ldots, \tau-1)$.

Let $h_{t}: M_{t} \rightarrow Z_{t}$ be an outcome function at time $t=1, \ldots, \tau$, which to every message $m_{t}$ (see (1)) assigns the allocation which is the result of analysis of message $m_{t}$ by economic agents. Set $Z_{t}$ means a set of outcomes of function $h_{t}$. The outcome function, assigning to every message

$$
m=\left(m_{1}, \ldots, m_{\tau}\right)
$$

an outcome, which is the result of retrieving and analysis of every message $m_{t}$ at time $t$ by economic agents, is of the form

$$
h=h_{1} \times \cdots \times h_{\tau} .
$$

\section{Definition 9 The structure}

$$
(M, f, h),
$$

where $M=M_{1} \times \cdots \times M_{\tau}, f=f_{1} \times \cdots \times f_{\tau-1}, h=h_{1} \times \cdots \times h_{\tau}$ is called the adjustment process.

The number of commodities in the economy under study can be changed in time. Let $\uparrow_{t} \in\{1,2, \ldots\}$ mean the dimension of the commodity space at time $t \in\{1, \ldots, \tau\}$. Without loss of generality, we can assume that $\uparrow_{1} \leq \cdots \leq \uparrow_{\tau}$. Let $K \stackrel{\text { def }}{=} A \cup B$ be the set of economic agents. For every $t$ and $\uparrow_{t}$ :

- $Y^{k}(t) \subset \mathbb{R}^{\uparrow_{t}} \times\{0\} \times \cdots \times\{0\} \subset \mathbb{R}^{\uparrow_{\tau}}$ means the set of plans of action of producer $k \in B$, feasible to realization at time $t$; if $k \notin B$, then $Y^{k}(t)=\{0\} \in \mathbb{R}^{\mathbb{I}_{\tau}}$,

- $y^{k}(t)$-the plan of producer $k$ feasible at time $t, y^{k}(t) \in Y^{k}(t), \tilde{y}^{k}(t)$-the plan realized at time $t$.

In the same way, the characteristics of consumers: $X^{k}(t) \subset \mathbb{R}^{\downarrow_{\tau}}$ and $x^{k}(t), \sim^{k}(t), \epsilon_{t}(k) \in \mathbb{R}^{\downarrow_{\tau}}$ are defined. The correspondence of preference relations at time $t$ is of the form: 


$$
\varepsilon_{t}(k)=\left\{\begin{array}{lll}
\preccurlyeq_{k}^{t} & \text { for } & k \in A \\
\{\varnothing\} & \text { for } & k \notin A,
\end{array}\right.
$$

where $\varepsilon_{t} \subset K \times\left(\mathbb{R}^{I_{\tau}} \times \mathbb{R}^{I_{\tau}}\right)$ and $\preccurlyeq_{k}^{t} \subset X^{k}(t) \times X^{k}(t)$ means the preference relation of agent $k$ at time $t$. Additionally, the vector $p(t) \in \mathbb{R}^{\downarrow_{t}} \times\{0\} \times \cdots \times\{0\} \subset \mathbb{R}^{\downarrow_{\tau}}$ means the price vector at time $t$, while the mapping $\theta_{t}: K \times K \rightarrow[0,1]$, satisfying

- $\theta_{t}(k, \cdot) \equiv 0$ for $k \notin A$,

- $\theta_{t}(\cdot, k) \equiv 0$ for $k \notin B$,

- $\forall b \in \widetilde{B}_{t}: \sum_{a \in \tilde{A}_{t}} \theta_{t}(a, b)=1$

is the share mapping at time $t$. On the basis of the above, the environment of every agent $k \in K$ at time $t$ is defined by

$$
e^{k}(t)=\left(Y^{k}(t), X^{k}(t), \varepsilon_{t}(k), \epsilon_{t}(k), \theta_{t}(k, \cdot)\right) .
$$

Consequently, the set of environments at time $t \in\{1, \ldots, \tau\}$ is of the form

$$
E^{k}(t)=P\left(\mathbb{R}^{\ell_{\tau}}\right) \times P\left(\mathbb{R}^{\ell_{\tau}}\right) \times P\left(\mathbb{R}^{2 \ell_{\tau}}\right) \times \mathbb{R}^{\ell_{\tau}} \times \mathcal{F}(K,[0,1]),
$$

where $\mathcal{F}(K,[0,1])=\{f: K \rightarrow[0,1]\}$. The components of environment

$$
e_{t}=\left(e^{k_{1}}(t), e^{k_{2}}(t), \ldots\right)
$$

in restriction to space $\mathbb{R}^{\uparrow t}$, where for every $k \in K$, the economic environment $e^{k}(t)$ defined in (3), with a price vector $p(t)$ in restriction to space $\mathbb{R}^{\downarrow t}$, determine economy $\epsilon_{q}(t)$ (see Definition 3) which is the transformation at time $t$ of economy $\epsilon_{q}(1)$. The plans of actions in economy $\epsilon_{q}(t)$ can be interpreted as information (messages) sent to other agents at time $t$ as the response for prices $p(t)$. Taking the above into consideration, a message of every agent $k \in K$ at time $=1, \ldots \tau, \tau \in\{2,3, \ldots\}$ is given by

$$
m^{k}(t) \stackrel{\text { def }}{=}\left(p(t), \tilde{y}^{k}(t), \tilde{x}^{k}(t)\right)
$$

for $t=1, \ldots, \tau$. The response function is of the form

$$
f_{t}^{k}\left(m_{t}, e_{t}\right)=m^{k}(t+1),
$$

where $m_{t}$ is, for $t=1, \ldots, \tau-1$, given by (1). So, in reply to prices $p(t+1)$, every agent $k$ chooses his plan of action at time $t+1$. The feasible plans of action at time $t+1$ form sets $Y^{k}(t+1)$ and $X^{k}(t+1)$, respectively.

To sum up the adjustment process of economy $\epsilon_{q}(1)$, for $\tau \in\{2,3, \ldots\}$, is determined by messages $m_{1}, \ldots, m_{\tau}$ satisfying (1), response functions $f_{1}, \ldots, f_{\tau-1}$ of the form (6) and outcome functions $h_{1}, \ldots, h_{\tau}$. By (6), it follows that economic environments $e_{2}, \ldots, e_{\tau}$ (see (4)) also influence on determination of the form of adjustment process (2). Instead of economic environments $e_{2}, \ldots, e_{\tau}$, we can consider economies $\epsilon_{q}(2), \ldots, \epsilon_{q}(\tau)$, formed by the components of environments $e_{2}, \ldots, e_{\tau}$ restricted to spaces $\mathbb{R}^{\downarrow_{2}}, \ldots, \mathbb{R}^{\downarrow_{\tau}}$, respectively, to further considerations. For $\tau>2$, economies 
$\epsilon_{q}(2), \ldots, \epsilon_{q}(\tau-1)$ can be interpreted as intermediate steps of the adjustment process (2).

The adjustment process of economy $\epsilon_{q}(1)$ can also consist of two steps, so every single step of the adjustment process (2) is the adjustment process of economy $\epsilon_{q}(t-1)$ into economy $\epsilon_{q}(t)$. The innovative changes can appear earlier than at time $\tau$. If so, then there exists $t \in\{2, \ldots, \tau\}$ such that $\epsilon_{q}(t-1) \subset_{i t} \epsilon_{q}(t)$. Thus the evolution on time interval $[0, \tau]$ of economy $\epsilon_{q}(1)$ has a uniform and coherent mathematical description.

Definition 10 Adjustment process (2) with economic environments (4), the messages of the form (5), the response functions given by (6) is called the transformation process of economy $\epsilon_{q}(1)$ with final transformation $\epsilon_{q}(\tau)$ and intermediate steps $\epsilon_{q}(2), \ldots, \epsilon_{q}(\tau-1)$ for $\tau>2$.

Below we show that a transformation process of economy $\epsilon_{q}(1)$, where $\epsilon_{q}(1)=\epsilon(1)$, can move an initial economy being in equilibrium to a new stationary state, where innovations, if any exist, have been absorbed in the equilibrated allocation as well as some harmful commodities or technologies have been eliminated from producers' activities. The last means that an eco-innovation is introduced on the market at $\tau=2$.

Example 1 Let $\epsilon(1)$ be an economy in equilibrium with commodity-price space $\mathbb{R}^{{ }_{1}}$. Consider a situation, when new products do not appear on the market in period [0,2] as well as at least one of the following conditions is satisfied:

a) Consumers do not want to consume some commodities any more,

b) Consumers do not want to have anything more to do with goods which are produced by the use of some technologies,

c) Some of goods are consumed in a constant proportion.

We will show that it is possible to get equilibrium at time $\tau=2$ in economy $\epsilon(\tau)$, in which

$$
X^{a}(\tau)=X^{a}(1), \varepsilon_{\tau}(a)=\varepsilon_{1}(a), \epsilon_{\tau}(a)=\epsilon_{1}(a), \theta_{\tau}(a, \cdot)=\theta_{1}(a, \cdot) \text { for } a \in A
$$

as a result of a transformation process of economy $\epsilon(1)$.

Solution The interpretations of conditions (a), (b) and (c) were analyzed in (Lipieta $2010,2015)$. However, for the convenience of the reader, they are also presented below.

Ad. a) If consumers are not interested in consumption of harmful or obsolete commodity $l \in\left\{1, \ldots, \uparrow_{1}\right\}$, at time $t=1$, then $l$ th coordinate in every consumption plan is equal zero. It means that

$\forall a \in A: X^{a}(1) \subset V=k e r \tilde{g}$

where $\quad \tilde{g}: \mathbb{R}^{\uparrow_{1}} \ni\left(x_{1}^{a}(1), x_{2}^{a}(1), \ldots, x_{\rfloor_{1}}^{a}(1)\right) \rightarrow x_{l}^{a}(1) \in \mathbb{R} \quad$ and ker $\tilde{g}=\left\{x \in \mathbb{R}^{\uparrow_{1}}: \tilde{g}(x)=0\right\}$. 
Ad. c) If quantities of two commodities $l, \tilde{l} \in\left\{1, \ldots, \uparrow_{1}\right\}$, where $l \neq \tilde{l}$, are proportional in consumers' plans at time $t=1$, then $c \cdot x_{\sim}^{a}(1)$

$\exists c \in \mathbb{R} \backslash\{0\} \forall a \in A \forall x^{a}(1)=\left(x_{1}^{a}(1), x_{2}^{a}(1), \ldots, x_{\uparrow_{1}}^{a}(1)\right) \in X^{a}(1): x_{l}^{a}(1)=$

Consequently, there exists a functional

$$
\tilde{g}: \mathbb{R}^{\ell_{1}} \ni\left(x_{1}^{a}(1), \ldots, x_{\ell_{1}}^{a}(1)\right) \rightarrow x_{l}^{a}(1)-c x_{\tilde{l}}^{a}(1) \in \mathbb{R}
$$

such that condition (8) is satisfied. In a general case, there exists a linear subspace $V$ of space $\mathbb{R}^{\uparrow_{1}}$ such that, for $t=1$,

$$
\forall a \in A: X^{a}(1) \subset V .
$$

Ad. b) In the model under study technologies are described by production plans. If consumers do not want to buy the commodities which are produced by the use of some detrimental technologies, their consumption sets might satisfy condition (9) for a subspace $V$.

Therefore, if conditions (a) or (b) or (c) are satisfied, then producers can decide to change their activities on the market.

For subspace $V$ of space $\mathbb{R}^{\uparrow_{1}}\left(\uparrow_{1}>1\right)$ there exist linearly independent vectors $g^{1}, \ldots, g^{d} \in \mathbb{R}^{\uparrow_{1}}\left(g^{s}=\left(g_{1}^{s}, \ldots, g_{\uparrow_{1}}^{s}\right), s \in\{1,2, \ldots, d\}, d \in\left\{1,2, \ldots, \uparrow_{1}-1\right\}\right)$, such that

$$
V=\cap_{s=1}^{d} \operatorname{ker} \tilde{g}^{s}
$$

where mapping

$$
\tilde{g}^{s}: \mathbb{R}^{\ell_{1}} \ni\left(x_{1}, \ldots, x_{\ell_{1}}\right) \rightarrow g_{1}^{s} x_{1}+\cdots+g_{\ell}^{S} x_{\ell_{1}} \in \mathbb{R}
$$

is, for every $s \in\{1, \ldots, d\}$, linear and continuous. If condition (a) is satisfied, then vector $g^{s}$ has exactly one coordinate different from zero. If (c) is satisfied, then vector $g^{s}$ has at least two coordinates different from zero. If (b) is satisfied, then vector $g^{s}$ has at least one coordinate different from zero.

As economy $\epsilon(1)$ is in equilibrium, then for price vector $p(1)=p \in \mathbb{R}^{\uparrow 1}$ there exist feasible allocation

$$
\left(\left(x^{a *}(1)\right)_{a \in A},\left(y^{b *}(1)\right)_{b \in B}\right),
$$

such that sequence $\left(\left(x^{a *}(1)\right)_{a \in A},\left(y^{b *}(1)\right)_{b \in B}, p\right)$ is the state of equilibrium in economy $\epsilon$ (1).

The above means that at price vector $p$, for every $b \in B, y^{b *}(1)$ maximizes the profit of producer $b$ as well as for every $a \in A, x^{a *}(1)$ maximizes the preference of consumer $a$ on his budget set. Moreover, allocation (10) is feasible, namely: 


$$
\zeta \stackrel{\text { def }}{=} \sum_{a \in A} x^{(a *)}(1)-\sum_{b \in B} y^{(b *)}(1)-\sum_{a \in A} \omega^{a}(1)=0
$$

Assume that (10) is the realized allocation, i.e., $\tilde{y}^{b}(1)=y^{b *}(1)$ and $\tilde{\sim}^{a}(1)=x^{a *}(1)$, for every $a \in A$ and $b \in B$.

Now such a procedure of modification of production sector is presented that modified production sets at time $\tau=2$ are contained in subspace $V$ as well as the economy at time $\tau$ is in equilibrium at price system $p(\tau)=p$. For $t=1$ and $k \in K$ the value of response function (6) consists of

$$
\begin{aligned}
& p(2)=p, \\
& y^{k}(2)=y^{k}(1)-\sum_{s=1}^{d} \tilde{g}^{s}\left(y^{k}(1)\right) \cdot q^{s}, \\
& x^{k}(2)=x^{k}(1)-\sum_{s=1}^{d} \tilde{g}^{s}\left(x^{k}(1)\right) \cdot q^{s},
\end{aligned}
$$

where vectors $q^{1}, \ldots, q^{d} \in \mathbb{R}^{\uparrow_{1}}$ are a solution of system of equations:

$$
\begin{aligned}
& \tilde{g}^{s}\left(q^{r}\right)=\delta^{s r} \text { for } s, r \in\{1, \ldots, d\} \\
& \text { and } \\
& \delta^{s r}= \begin{cases}1 & \text { if } s=r \\
0 & \text { if } s \neq r\end{cases}
\end{aligned}
$$

is Kronecker delta. Adjustment process (2), in which

- for $\tau=2$, environments (4) satisfy (7),

- agents' messages are of the form (5) with production and consumption plans at time $\tau=2$ given by (12) and (13) for some $q^{1}, \ldots, q^{d}$,

- the response functions are defined in (6),

- the outcome sets, for $t=1,2$, are of the form:

$$
Z_{t} \stackrel{\text { def }}{=}\left\{\begin{array}{l}
\left(\left(x^{a}(t)\right)_{a \in A},\left(y^{b}(t)\right)_{b \in B}, p(t)\right): x^{a}(t) \in \varphi_{t}^{a}(p), y^{b}(t) \in \eta_{t}^{b}(p) \\
\sum_{a \in A} x^{a}(t)-\sum_{b \in B} y^{b}(\tau)=\sum_{a \in A} \omega^{a}(t), p(t)=p,
\end{array}\right\},
$$

- outcome functions, for $t=1,2$, satisfy

$$
h_{t}\left(m_{t}\right) \stackrel{\text { def }}{=} h_{t}\left(\left(p(t), y^{k_{1}}(t), x^{k_{1}}(t)\right),\left(p(t), y^{k_{2}}(t), x^{k_{2}}(t)\right), \ldots\right)=\left(\left(x^{a}(t)\right)_{a \in A},\left(y^{b}(t)\right)_{b \in B}, p(t)\right)
$$

is the transformation process of economy $\epsilon(1)$ (see Definition 10). That process is denoted by $\Lambda\left(q^{1}, \ldots, q^{d}\right)$. We say that vectors $q^{1}, \ldots, q^{d}$ determine the direction of the process $\Lambda\left(q^{1}, \ldots, q^{d}\right)$. In the same way as in the proof of Theorem 4.2 in Lipieta (2010), 
it can be proved that transformation process $\Lambda\left(q^{1}, \ldots, q^{d}\right)$ results in equilibrium in economy $\epsilon(\tau), \tau=2$, as well as sequence

$$
\left(\left(x^{a *}(\tau)\right)_{a \in A},\left(y^{b *}(\tau)\right)_{b \in B,}, p\right)
$$

where

$$
x^{a *}(\tau)=x^{a *}(1)-\sum_{s=1}^{d} \tilde{g}^{s}\left(x^{a *}(1)\right) \cdot q^{s} \text { and } y^{b *}(\tau)=y^{b *}(1)-\sum_{s=1}^{d} \tilde{g}^{s}\left(y^{b *}(1)\right) \cdot q^{s}
$$

is the state of equilibrium in economy $\epsilon_{q}(\tau)$. Production sets from economy $\epsilon(1)$, for every $b \in B$, are transformed to sets

$$
Y^{b}(\tau)=\left\{y^{b}(1)-\sum_{s=1}^{d} \tilde{g}^{s}\left(y^{b}(1)\right) \cdot q^{s}: y^{b}(1) \in Y^{b}(1)\right\} .
$$

The characteristics of consumption system of economy $\epsilon_{q}(2)$ are the same as in economy $\epsilon_{q}(1)$. In the above situation:

- if, for every $b \in B, Y^{b}(2) \subset \bigcup_{b \in B} Y^{b}(1)$, then $\epsilon(1) \subset_{\text {imt }} \epsilon(2)$; consequently transformation process $\Lambda\left(q^{1}, \ldots, q^{d}\right)$ may be regarded as imitative,

- if, for every $b \in B, Y^{b}(1) \subset Y^{b}(2)$ and $Y^{b}(2) \subset \bigcup_{b \in B} Y^{b}(1)$, then transformation process $\Lambda\left(q^{1}, \ldots, q^{d}\right)$ may be regarded as cumulative,

- if there exists $b \in B$ such that $Y^{b}(2) \not \subset \bigcup_{b \in B} Y^{b}(1)$, then $\epsilon(1) \subset_{i t} \epsilon(2)$ and process $\Lambda\left(q^{1}, \ldots, q^{d}\right)$ may be regarded as innovative.

At the end, let us notice that to get equilibrium in economy $\epsilon$ (2) a person or an institution established by an unspecified decision-maker, should determine a direction (vectors $\left.q^{1}, \ldots, q^{d}\right)$ of the transformation process presented.

In Example 1, we design an adjustment process transforming economy $\epsilon(1)$ being in equilibrium into such economy $\epsilon(\tau)$ in which there is equilibrium at the same prices as well as

$$
\forall b \in B \quad Y^{b}(\tau) \subset V .
$$

Example 1 shows that it is possible to guide the economic system being in the form of the circular flow into its transformation also being in the form of the circular flow introducing eco-changes into production sphere. Thus, if $\Lambda\left(q^{1}, \ldots, q^{d}\right)$ is innovative, then an eco-innovation is introduced at time $\tau=2$. The production sets satisfying the above condition are called the linear production sets (Moore 2007). Finally, it should be added that the assumptions considered by Arrow and Debreu (1954) were not assumed for economy $\epsilon(1)$. 


\section{Mechanisms of economic evolution as the components of the adjustment process}

On competitive markets, the economic agents do not behave strategically and they do not cooperate. In the spirit of the perfect rationality assumptions (Simon 1955), producers and consumers realize their optimal plans of action, while according to the bounded rationality conditions, innovators realize or will realize their innovative plans. Innovators introduce new products or new technologies into production to get higher profits now or in the future. Thus, now or in the near future, profits may not be increased. Ecoinnovators introduce eco-innovations above all to protect the environment and only in the second instance, if at all, to increase the profits.

In the model under study, if innovators do not operate in a given period, then the aim of economic agents is to realize the plans of action which guarantee maximum profits or maximizing the preferences on the budget sets, respectively. If the economy is in equilibrium as well as the producers do not have ideas for creating new commodities or implementation new technologies, etc., to increase the profits, then the economic agents do not have motivations to change their plans of action. That is why, in the model considered, only innovators or the influence of external factors can move an economy from its equilibrium state. In this research, we focus only on the innovators' activities.

To analyze and to explore the nature of economic evolution, the Hurwicz's economic mechanisms (see for instance Hurwicz and Reiter 2006) were used in our previous research. It enabled us to emphasize the role of information within economic processes as well as distinguish price, qualitative and adapting mechanisms among all possible economic mechanisms of economic evolution (Lipieta and Malawski 2016).

First, we recall the definition of the economic mechanism in the sense of Hurwicz. Let $E \neq \varnothing$ be a set of economic environments, $Z$-a set of outcomes.

Definition 11 (Hurwicz and Reiter 2006). The triple $\Gamma=(M, \mu, h)$, where

$$
\begin{aligned}
& M \neq \varnothing \text { is the message space, } \\
& \mu: E \rightarrow M \text { is the message correspondence, } \\
& h: M \rightarrow Z \text { is the outcome function }
\end{aligned}
$$

is called the mechanism in the sense of Hurwicz or the Hurwicz mechanism.

Below the relationship between Hurwicz mechanisms and the transformation process of a private ownership economy with almost all inactive agents (see Definition 10 ) is indicated. Let $\tau \in\{2,3, \ldots\}$ and $t \in\{1,2, \ldots \tau\}$. It is proved that a transformation process of economy is a sequence of adequate Hurwicz mechanisms (compare to Hurwicz 1987).

Theorem 1 (compare to Hurwicz 1987). Let $(M, f, h)$ be a transformation process of economy $\epsilon_{q}(1)$ with intermediate steps $\epsilon_{q}(2), \ldots, \epsilon_{q}(\tau-1)$. For $t=2, \ldots, \tau-1$, the transformation process of economy $\epsilon_{q}(t)$ into economy $\epsilon_{q}(t+1)$ is a mechanism in the sense of Hurwicz. 
The mechanism $\Gamma_{t}$, fort $=1, \ldots, \tau-1$, defined in the proof of Theorem 1 (see Appendix) is not static: message correspondence $\mu_{t}$ assigns to the environment at time $t$, messages at time $t+1$. That property allows us to conclude, among others, that available information on agents' activities influence on their market decisions in the future. For $t=1, \ldots, \tau-1$ and economies $\epsilon_{q}(t) \subset \epsilon_{q}(t+1)$, mechanism $\Gamma_{t}$ defined in the proof of Theorem 1 is called:

- the imitative mechanism, if $\epsilon_{q}(t) \subset_{\text {imt }} \epsilon_{q}(t+1)$,

- the cumulative mechanism, if $\epsilon_{q}(t) \subset_{c t} \epsilon_{q}(t+1)$,

- the innovative mechanism, if $\epsilon_{q}(t) \subset_{i t} \epsilon_{q}(t+1)$,

- the regressive mechanisms, if $\epsilon_{q}(t) \subset_{r t} \epsilon_{q}(t+1)$.

On the basis of the above reasoning, the following can be concluded:

- if $\Gamma_{t}$ is an imitative mechanism and $\epsilon_{q}(t) \neq \epsilon_{q}(t+1)$, then $\Gamma_{t}$ carries only in significant changes into agents' economic activities,

- if $\epsilon_{q}(t)=\epsilon_{q}(t+1)$, then also $\epsilon_{q}(t) \subset_{c t} \epsilon_{q}(t+1)$; in such a case, economic agents do not change their activity on markets in the period from $t$ to $t+1$.

Combining the results of the Example 1 and Theorem 1, we easy conclude that an ecomechanism can be implemented at every step of an adjustment process. Dependently on initial conditions and prices that mechanisms can be innovative, imitative, cumulative or regressive. Below further examples of mechanisms in the sense of Hurwicz are presented. Those examples take the form of mathematical theorems and correspond to Schumpeter's description of economic evolution. In the proof of the following theorem, an explanation, why a private ownership economy with almost all inactive agents, which is an example of an economic organizational structure, is a mechanisms in the sense of Hurwicz, can be found. The idea of the proof relies on the interpretation of realized allocations as messages and outcomes of the mechanism under study. Firstly, the following is proposed.

Remark 2 The economy $\epsilon_{q}(t)$, in which for $t=1, \ldots, \tau$,

$$
Z_{t}=\left\{\left(\left(x^{a}(t)\right)_{a \in A},\left(y^{b}(t)\right)_{b \in B}, p(t)\right): \sum_{a \in A} x^{a}(t)=\sum_{b \in B} y^{b}(t)+\omega(t)\right\} \neq \emptyset
$$

is a mechanism in the sense of Hurwicz.

In contrast to Theorem 1, the mechanism defined in the proof of Remark 2 (see Appendix) is static: message correspondence $\mu_{t}$ assigns to the environment at time $t$, messages at the same time. That mechanism is eco-mechanism if

$$
\forall b \in B \quad y^{b *}(\tau) \in V \text { and } \forall a \in A \quad x^{a *}(\tau) \in V,
$$

where subspace $V$ is determined by one of the conditions (a), (b) or (c) analyzed in Example1. 
If every producer maximizes his profit $\left(P_{q}=P\right)$ and every consumer maximizes his preference on the budget set $\left(C_{q}=C\right)$, then it can be also proved that the economy $\epsilon_{q}=\epsilon$ is a Hurwicz mechanism. However, in that case, the agents' aims are different. Hence the set of messages is defined in another way, i.e.,

$$
M_{t}=\left\{\begin{array}{l}
m_{t}=\left(m^{k_{1}}(t), m^{k_{2}}(t), \ldots\right): \\
m^{k}(t) \stackrel{\text { def }}{=}\left(p(t), y^{k}(t), x^{k}(t)\right) \wedge x^{a}(t) \in \varphi_{t}^{a}(p(t)) \wedge y^{b}(t) \in \eta_{t}^{b}(p(t))
\end{array}\right\} .
$$

Mechanism defined in Remark 2 does not make positions of economic agents worse because producers and consumers realize their optimal plans of action in given environments. Therefore, it is concluded that the mechanism defined in Remark 2 is the cumulative mechanism, which additionally confirms that every economy $\epsilon_{q}(t)$ is in the form of the circular flow.

Now, we focus on modeling some examples of mechanisms resulting in equilibrium in the economy under study. Assuming that at some prices, every agent can realize his aims, i.e., producers maximize profits, consumers maximize preferences on the budget sets, we will show how to reach equilibrium in a transformation of the initial economy under some additional mathematical assumptions interpreted in economic theory.

Let $\tau \in\{2,3, \ldots\}, t \in\{1, \ldots, \tau\}, \uparrow=\uparrow_{\tau} \in\{1,2, \ldots\}$ and $p \in \mathbb{R}^{\uparrow}$. Let $\epsilon_{q}(t)$ be an economy with commodity-price space $\mathbb{R}^{\mathfrak{I}}$. Consider allocation $\left(\left(x^{a *}(t)\right)_{a \in A},\left(y^{b *}(t)\right)_{b \in B}\right)$ (see (10)), where at price system $p, y^{b *}(t) \in \eta_{t}^{b}(p)$, for every $b \in B$, as well as $x^{a *}(t) \in \varphi_{t}^{a}(p)$, for every $a \in A$. Suppose that allocation (10) is not feasible at time $t$, namely

$$
\zeta \stackrel{\text { def }}{=} \sum_{a \in A} x^{a *}(t)-\sum_{b \in B} y^{b *}(t)-\sum_{a \in A} \omega^{a}(t) \neq 0
$$

Below, under the assumption that the difference between the total demand and the total endowment can be realized by producers, we show that if $p(t+1)=p$, then economy at time $t+1$ is in equilibrium. Moreover, if $p(t)=p$, then $\epsilon_{q}(t)=\epsilon_{q}(t+1)$.

Theorem 2 If (16) is satisfied,

$$
p \circ \zeta=0
$$

as well as

$$
\sum_{a \in A} x^{a *}(t)-\sum_{a \in A} \omega^{a}(t) \in Y^{b_{1}}(t)+\cdots+Y^{b_{n}}(t)
$$

then there exists a cumulative mechanism $\Gamma_{t}$ which results in equilibrium at price vector $p(t+1)=p$, in economy $\epsilon_{q}(t+1)$ in which characteristics of economic agents are the same as in economy $\epsilon_{q}(t)$.

Proof Let us firstly note that, if (18) is valid, then there exist vectors $\zeta^{b_{1}}, \ldots, \zeta^{b_{n_{t}}} \in \mathbb{R}^{\downarrow}$, such that

$$
\zeta=\zeta^{b_{1}}+\cdots+\zeta^{b_{n_{t}}}
$$


and

$$
y^{b_{j} *}(t)+\zeta^{b_{j}} \in Y^{b_{j}}(t) \text { for every } j \in 1, \ldots, n_{t} .
$$

We show that

$$
p \circ \zeta^{b_{j}} \leq 0 \text {, for every } j \in 1, \ldots, n_{t} \text {. }
$$

Indeed, by (18), for every $j \in\left\{1, \ldots, n_{t}\right\}$,

$$
p \circ\left(y^{b_{j} *}+\zeta^{b_{j}}\right) \leq p \circ y^{b_{j} *} .
$$

By (21) and (17), we get that

$$
p \circ \zeta^{b_{j}}=0 \text { for every } j \in 1, \ldots, n_{t},
$$

and consequently

$$
y^{b_{j} *}+\zeta^{b_{j}} \in^{b_{j}}(p) \text {. }
$$

Now we define a mechanism resulting in equilibrium in economy $\epsilon_{q}(t)$. For every $k \in K:$

- the environment $e^{k}(t)$ is of the form (3),

- the message of agent $k$ is of the form $m^{k}(t+1)=\left(p(t+1), \widetilde{\sim}^{k}(t+1), \sim_{x}^{k}(t+1)\right)$, where:

$$
\begin{aligned}
& p_{k}(t+1)=p, \\
& \mathcal{x}^{k}(t+1)=x^{k *}(t), \text { if } k \in A, \\
& \widetilde{x}_{k}(t+1)=0, \text { if } k \notin A, \\
& \widetilde{y}^{k}(t+1)=0 \text {, if } k \notin B, \\
& \tilde{y}_{k}(t+1)=y^{k *}(t)+\zeta^{k}, \text { if } k=b_{j} \text { for } j \in\left\{1, \ldots, n_{t}\right\}, \\
& y(t+1)=0, \text { if } k=b_{j} \text { for } j \in\left\{n_{t}+1, n_{t}+2, \ldots\right\},
\end{aligned}
$$

- the message correspondence of agent $k$ is of the form:

$$
\mu_{t}^{k}\left(e^{k}(t)\right)=m_{t+1}=\left(\left(p, \tilde{y}^{k_{1}}(t+1), \tilde{x}^{k_{1}}(t+1)\right),\left(p, \tilde{y}^{k_{2}}(t+1), \tilde{x}^{k_{2}}(t+1)\right), \ldots\right)
$$

- the outcome set (not empty by (18), (19) and (22))

$$
Z_{t+1}=\left\{\begin{array}{l}
\left(\left(x^{a}(t+1)\right)_{a \in A},\left(y^{b}(t+1)\right)_{b \in B}, p(t+1)\right): \\
\sum_{a \in A} x^{a}(t+1)-\sum_{b \in B} y^{b}(t+1)=\omega(t+1), \\
x^{a}(t+1) \in \varphi_{t+1}^{a}(p(t+1)), y^{b}(t+1) \in \eta_{t+1}^{b}(p(t+1)) .
\end{array}\right.
$$

Next, the outcome function:

$$
h_{t+1}\left(m_{t+1}\right)=\left(\left(\tilde{x}^{a}(t+1)\right)_{a \in A},\left(\tilde{y}^{b}(t+1)\right)_{b \in B}, p(t+1)\right)
$$

is determined. Moreover, by (18), (19) and (22), sequence 


$$
\left(\left(x^{a *}(t)\right)_{a \in A},\left(y^{b *}(t)+\zeta^{b}\right)_{b \in B}, p\right),
$$

in which $\zeta^{b}=0$, for $b=b_{j}$ where $j \in\left\{n_{t}+1, n_{t}+2, \ldots\right\}$, is the state of equilibrium in economy $\epsilon_{q}(t+1)$ determined by set $e^{k}(t+1)=e^{k}(t)$, at price vector $p(t+1)=p$.

Economies $\epsilon_{q}(t)$ and $\epsilon_{q}(t+1)$ differ only with prices. Hence, if $p(t)=p$, then $\epsilon_{q}(t+1)=\epsilon_{q}(t)$. Assumption (16) means that optimal plans $\left(x^{a *}(t)\right)_{a \in A},\left(y^{b *}(t)\right)_{b \in B}$ at prices $p(t)=p$, do not satisfy market clearing condition. For this reason sequence $\left(\left(x^{a *}(t)\right)_{a \in A},\left(y^{b *}(t)\right)_{b \in B}, p\right)$ is not a state of equilibrium in economy $\epsilon_{q}(t)=\epsilon(\mathrm{t})$. Assumption (17) means that sequence $\left(\left(x^{a *}(t)\right)_{a \in A},\left(y^{b *}(t)_{b \in B}, p\right)\right.$ satisfies Walras Law, whereas assumption (18) indicates that excess or deficiency of some commodities on markets can be fulfilled by producers' activity. The mechanism defined in the proof of Theorem 2 relies on changing producers' activities under feasible technologies at time $t$, to cover surpluses or deficiencies of commodities revealing in total consumption plan $x^{*}(t)$ compared to total endowment $\omega(t)$.

It can be noticed that, under the assumption $p(t)=p$, the mechanism defined in the proof of Theorem 2 is the cumulative mechanism in which maximal profits are not changed although this mechanism requires some changes in producers' activities (conditions (22) and (23)). Hence, in that case the economic positions of economic agents are not worse. If in the economy satisfying assumptions of Theorem 2, there exist $b_{0} \in B$ such that $y^{b_{0} *}(t)+\zeta \in Y^{b_{0}}(t)$, which means that in decomposition (19), $\zeta^{b}=\zeta$ for $b=b_{0}$ and $\zeta^{b}=0$ for $b \neq b_{0}$, then the mechanism defined in the proof of Theorem 2 requires only from producer $b_{0}$ to change his market activity. By the above sequence $\left(\left(x^{a *}(t)\right)_{a \in A}, y^{b}(t)_{b \in B}, p\right)$, where
$\breve{y}^{b}(t)=\left\{\begin{array}{l}y^{b *}(t) \text { for } b \neq b_{0} \\ y^{b *}(t)+\zeta \text { for } b=b_{0}\end{array}\right.$

is the state of equilibrium in economy $\epsilon_{q}(t+1)=\epsilon(t)$.

The classification of mechanisms defined in the proof of Theorems 1 depends on the relationships between characteristics of economic agents at time $t+1$ with respect to time $t$, while the mechanisms defined in the proof of Theorem 2 belong to the group of mechanisms resulting in equilibrium in the economy. Above all, due to Theorem 2, it can be seen that, under some assumptions, the economy under study can be in equilibrium at an intermediate or at the ending point of the process of transformation.

At the end, we show that if the difference between the total demand and the total endowment cannot be fulfilled by producers under feasible technologies, then $p$ would be the equilibrium price vector in an innovative transformation of economy $\epsilon_{q}(t)$. As earlier, we assume that there is an allocation $\left(\left(x^{a *}(t)\right)_{a \in A},\left(y^{b *}(t)\right)_{b \in B}\right)$ (see (10)), where at price system $p, y^{b *} \in \eta_{t}^{b}(p)$, for every $b \in B, x^{a *} \in \varphi_{t}^{a}(p)$, for every $a \in A$, which means that $\epsilon_{q}(t)=\epsilon(t)$.

Theorem 3 Suppose that conditions (16) and (17) are satisfied. If (18) is not satisfied, then there exists an innovative mechanism $\Gamma_{t}$ which results in equilibrium at price 
system $p(t+1)=p$, in economy $\epsilon_{q}(t+1)$, which is such a transformation of economy $\epsilon_{q}(t)$ in which consumers' characteristics are the same as in economy $\epsilon_{q}(t)$.

Proof As condition (18) is not satisfied, then there exists a sequence $\zeta^{b_{1}}, \ldots, \zeta^{b_{n}} \in \mathbb{R}^{\mathfrak{l}}$, satisfying (19), (22) as well as

$$
\zeta^{b_{j}} \neq 0 \Rightarrow y^{b_{j *} *}(t)+\zeta^{b_{j}} \notin \cup_{b \in B} Y^{b}(t) \text { for at least one } j \in 1, \ldots, n_{t} .
$$

For instance, a sequence of the form

$$
\zeta^{b_{1}}=\zeta, \zeta^{b_{2}}=\cdots=\zeta^{b_{n}}=0
$$

satisfies properties (19), (22) and (24).

The consumption sets, preferences and endowments at time $t+1$ are assumed to be the same as at time $t$, while

$$
Y^{b_{j}}(t+1)=Y^{b_{j}}(t)+\left\{\zeta^{b_{j}}\right\} \text { for } j \in 1, \ldots, n_{t} .
$$

Components of mechanism $t$ are defined in the same way as in the proof of Theorem 2.

By the above, $\epsilon_{q}(t+1)=\epsilon(t+1)$ where sequence

$$
\left(\left(x^{a *}(t+1)\right)_{a \in A},\left(y^{b *}(t+1)+\zeta^{b}\right)_{b \in B}, p\right),
$$

in which $\zeta^{k}=0$ for $k=b_{j}$ and $j \in\left\{n_{t}+1, n_{t}+2, \ldots\right\}$ is the state of equilibrium in economy $\epsilon(t+1)$. Consequently, mechanism $\Gamma_{t}$ is innovative.

The producers satisfying (25) are innovators. Innovativeness of producers revealing within the mechanism defined in Theorem 3 is the result of disequilibrium on markets of some commodities. The mechanism defined in Theorem 3 could change the position of some economic agents. For instance, if $0 \leq p(t)=\alpha \cdot p$, for $0<\alpha<1$, then the maximal profit of producer $b$ for which $p \circ y^{b *}(t)>0$ increases at time $t+1$. However, if $p(t)=p$, then producers' plans maximizing profits, consumers' plans maximizing their preferences on budget sets at time $t$ remain the same as at time $t$. Consequently, maximal profits stay at the same level. It could be caused by too high costs of introducing innovations with regard to their prices. Hence it is worth studying innovative mechanisms which will generate small changes into production activities. The distribution $\zeta^{b_{1}}, \ldots, \zeta^{b_{n}}$ of vector $\zeta$ satisfying conditions (19), (22) and (24) is not the only one, hence in some cases it seems to be possible to specify such a mechanism for which the changes to be introduced are sufficiently small in the given metrics.

The mechanisms defined in the proofs of Theorem 2 or Theorem 3 are eco-mechanisms, if, as earlier,

$$
\forall b \in B \quad y^{b *}(t+1) \in V
$$


where subspace $V$ is determined by one of the conditions (a), (b) or (c) analyzed in Example 1. Let us notice that, at given prices, maximal profits and plans maximizing consumers' preferences on budget set would be the same in both cases: as a result of an eco-mechanism or without any changes in agents' activities.

At the end, we present an example of the mechanism defined in the proof of Theorem 3 which results in equilibrium in a transformation of economy $\epsilon_{q}(t)$. As we will see, in economy $\epsilon_{q}(t)$ neither the assumptions considered in Example 1 nor the assumptions posted by Arrow and Debreu (1954) are satisfied.

Example 2 Consider a private ownership economy $\epsilon_{q}(t)$ with two commodities, one producer and one consumer. The characteristics of economic agents are the following:

$$
\begin{aligned}
& X^{1}(t)=[0, \infty) \times[0,8], \omega^{1}(t)=(2,3),\left(x_{1}, x_{2}\right) \preccurlyeq_{1}^{t}\left(\tilde{x}_{1}, \tilde{x}_{2}\right) \Leftrightarrow \max \left\{x_{1}, x_{2}\right\} \leq \max \left\{\tilde{x}_{1}, \tilde{x}_{2}\right\}, \\
& Y^{1}(t)=(-\infty,-1] \times(-\infty, 10] .
\end{aligned}
$$

Below we

(1) show that there is no equilibrium in economy $\epsilon_{q}(t)$,

(2) design a mechanism which leads, at prices $p=(1,1)$, to equilibrium in a transformation of economy $\epsilon_{q}(t)$.

Solution In economy $\epsilon_{q}(t)$ some assumptions of the First Existence Theorem for Competitive Equilibrium (Arrow and Debreu 1954, p. 266) are not satisfied i. e. set $Y(t)=Y^{1}(t)$ does not satisfy assumptions I.b, I.c (ibid. p. 267), the utility function determined by preference relation $\preccurlyeq_{1}^{t}$ does not satisfy assumption III.c (ibid. p. 269). We show that at any price system there is no equilibrium in that economy.

Ad. 1) The producer can maximize his profit, if an only, if $p_{1} \geq 0$ and $p_{2} \geq 0$.

If $p_{2}=0$, then the consumer does not maximize his preference on the budget set.

If $p=\left(0, p_{2}\right)$ for $p_{2}>0$, then $y^{1 *}=\left(y_{1}, 10\right)$ and $y_{1} \leq-1$. If $x^{*}(t)-y^{*}(t)=\omega(t)$, then $x^{*}(t)=y^{*}(t)+\omega(t)$. However, $y^{*}(t)+\omega(t)=\left(y_{1}+2,13\right) \notin X^{1}(t)$.

If $p_{1}>0$ and $p_{2}>0$, then $y^{1 *}(t)=(-1,10)$. If $x^{*}(t)-y^{*}(t)=\omega(t)$, then $y^{*}(t)+\omega(t)=x^{1 *}(t)=(1,13)$. Vector $(1,13) \notin X^{1}$.

By the above there is no equilibrium in economy $\epsilon_{q}(t)$. Moreover, condition (9) is not satisfied in that economy.

Ad. 2) Consider price vector $p=(1,1)$. Hence $y^{1 *}=(-1,10), x^{1 *}=(14,0)$ and $\zeta=(13,-13)$. We can see that in economy $\epsilon_{q}(t)$ assumption (17) is valid, while condition (18) is not satisfied. Following Theorem 3, we put: $Y^{1}(t+1)=Y^{1}(t)+\{(13,-13)\}$, $X^{1}(t+1)=X^{1}(t), \preccurlyeq_{1}^{t+1}=\preccurlyeq_{1}^{t}, \omega^{1}(t+1)=\omega^{1}(t)$ and $p(t+1)=(1,1)$. It is not difficult 
to check that economy $\epsilon_{q}(t+1)$, determined by the above characteristics, is in equilibrium at price system $p(t+1)=p$. The mechanism is defined in the same way as in the proof of Theorem 2 .

Remark 3 The mathematical set-up presented above leads us to specifying the relationship between the circular flow and the economic development. Within the evolution of the economy, cumulative or regressive or innovative mechanisms appear. Economic evolution can be viewed as a sequence of Hurwicz mechanisms which includes at least one innovative mechanism and a cumulative mechanism is the first element in that sequence. On the basis of the above, due to the use of the tools of Hurwiczian theory, we can conclude, that the circular flow is an environment, or an intermediate point, or an outcome of the economic development.

\section{Discussion}

In the Schumpeter's vision of the economic development innovations are endogenous and the key role is played by entrepreneurs-innovators (Schumpeter 1934, p. 63). Schumpeter argues that entrepreneurs-innovators, according to their creative nature, break the circular flow introducing innovation in the economy due to which they initiate and carry the economic development. To satisfy wants, both spiritual (i.e., satisfaction with introducing innovations) or material (i.e., increasing profits) entrepreneurs-innovators compete against each other in introducing new commodities, new technology, etc., on the market (see Schumpeter 1934, pp. 81-94). Similarly in the model presented, innovations are endogenous, some heterogenous producers, instead of aiming at the profit maximization, may undertake some innovative activities and realize the production plans which offers the possibility of future profits. Consequently, entrepreneurs-innovators are the initiators and leaders of economic evolution, whereas consumers play passive role. However, just like in Schumpeter's theory, in the model consumers can induce innovative changes and play the key role in the spread the innovations.

The approach proposed in the current paper significantly differs from the traditional models used for studying the economic evolution (see for example Aghion and Howitt 1992, 1998; Romer 2012; Dosi et al. 2010). The use of Hurwicz's apparatus emphasized the significant role of information for appearance of innovation and the ways of its exchanging. In the model presented, innovation emergences as a response to information on, among others, consumers' likes and requirements. Analyzing of information, which nowadays, is spread almost immediately, can provide entrepreneurs-innovators with new ideas, without which there is no innovation. Schumpeter maintained that "changes in economic life as are not forced upon it from without but arise by its own initiative from within." (Schumpeter 1934, p. 63). The "not forced" changes can be inspired, above all, by messages sent by economic agents. Therefore, the concept of studying innovations as the results of information available on the market corresponds to Schumpeter's theory of innovation. 
If a new commodity emergences on the market, then there will be no equilibrium in the economy in the next period. However, if the innovation is successful, then it will lead to changes in the economic environments and could change profits and utilities. In that period, the following actions can take place: some next innovations can be introduced, or the economy can reach a new state of equilibrium, or the economy can be transformed to its imitative or regressive transformation. Thus in the model presented, the impact of innovations on economic environments is revealed: as a result of emergence of innovations and their diffusion, the economic environments evolve. It is the equivalent of the "ripple effect" observed in simulations models. If innovative eco-mechanisms are implemented, then eco-changes as well as ecological economic activities are seen in the model.

We will deal with Schumpeterian swarming of innovations in the model, if the numbers of innovations introduced in subsequent periods are much higher than in earlier periods. Modeling of the swarm of innovations is feasible due to density of the set of real numbers. The effects of the creative destruction can also be analyzed in the model. It is seen, among others, in introducing innovations as well as in eliminating some commodities or firms from the market.

\section{Conclusions}

Modeling mechanisms of economic evolution in the Hurwicz's apparatus confirms the Day's ideas (2007) on the differences between mechanisms within the circular flow and the economic development, as well as contrary to the Schumpeter's concept, showed that mechanisms governing the innovative and non-innovative processes are naturally divided into more than two groups. What is more, it was shown that at every stage of the economic evolution eco-mechanisms can be implemented. The eco-mechanisms defined in the paper in many cases can improve the position of economic agents. Moreover, if an eco-mechanism were not be implemented, then the agents' economic position would not be better.

The model presented reveals the significant role of information and the ways of exchanging messages during innovative processes. Diversification of analyzed mechanisms reflects the complexity of economic processes and their results. In the set of outcomes of an innovative mechanism, the effects of creative destruction are also revealed; besides new commodities, technologies and organizational structures visible on the market, the old, unattractive or harmful products and technologies as well as the uncompetitive in a new economic reality firms, can disappear from the market.

In contrast to many other studies on evolutionary processes in economics, in the current paper the problem of incentives of economic agents can be analyzed. In the model presented, it is assumed that ecological consumers do not want to consume harmful commodities or commodities produced by the use of detrimental technologies. It makes producers modify their activities to become ecological and friendly to the environment. In that approach, a role of planners of economic life should not be neglected: a role of a decision-maker is to specify goals and choose a proper mechanism to be implemented, preferable in such a way that producers active in their own interest and eco-changes are introduced. We presented the examples of mechanisms in a competitive economy 
(Example 1, Theorem 2, Theorem 3) which could result in eco-changes or in equilibrium in a competitive economy or in its transformation.

The axiomatic method, assuming the rationality assumption of behavior of economic agents and the principle ceteris paribus, lets isolate the objects under study from the rest of the world. It plays a specific role in empirical economics indicating the objects and variables worth verifying by empirical methods. Simulation models in economics are often designed by the use of the concept of differential equations, which need to make many, often strong assumptions (such as exact formulas or differentiability), on the functions applied. Simulation models are developed for complex systems, each of them concern a specific situation and often are built on the basis of statistical data. Therefore, a firm or a whole economic system is able to be modeled by the use of a simulation model. However, as every economic model, a simulation model is a simplified description of reality, designed to analyze hypotheses about economic behavior that can be tested. In simulation models, to model various structures or processes different tools are often employed and that is why, in most cases, it is difficult to compare the simulation models with respect to the outcomes, costs, etc. The model presented in the current paper can be used for modeling a wider class of structures than in case of a simulation model. Additionally, it enables us to avoid unrealistic assumptions on utility functions or economic processes. In the presented approach structures, firms and processes can be modeled by the use of the same apparatus and due to that they can be compared, but the analyzed model is difficult to be tested. It could be used, for example, if the access to statistical data is limited or there is a need to compare some structures or processes. At the end, we emphasize that in the model presented the problem of incentives of economic agents can be analyzed which is not a subject of the study of simulation models.

Axiomatization of mechanisms of the evolution of the economy by the use of Hurwicz's apparatus exposed the positive, from the producers' and consumers' points of view, qualitative properties of the examined mechanisms. Moreover, it gave us the criterion for identifying in the set of analyzed mechanisms, the qualitative mechanisms with respect to the given set of agents, i.e., the mechanisms in which at least one agent from the given set would be better off due to a given criterion, without making the rest of agents from this set worse off.

Specification of an optimal eco-mechanism towards equilibrium considering agents' incentives remains under our research perspectives.

\section{Appendix: Remaining proofs}

Proof of Theorem 1 To prove the theorem, we have to identify the components of a mechanism in the sense of Hurwicz at every single step $t=1, \ldots, \tau-1$ of transformation process of $(M, f, h)$ of economy $\epsilon_{q}(1)$ by the use of its components. We define:

- $e^{k}(t)$-the economic environment of agent $k$ at time $t=1, \ldots, \tau$ of the form (3);

- $E^{k}(t)$-the set of all feasible economic environments of agent $k$ at time $t=1, \ldots, \tau$, $e^{k}(t) \in E^{k}(t)$ 
- $e_{t}=\left(e^{k_{1}}(t), e^{k_{2}}(t), \ldots\right)$, the economic environment at time $t=1, \ldots, \tau$

- $E_{t} \stackrel{\text { def }}{=} E^{k_{1}}(t) \times E^{k_{2}}(t) \times \ldots$-the set of economic environments at time $t=1, \ldots, \tau$, $e_{t} \in E_{t}$,

- $M_{t}=\left\{m_{t}=\left(m^{k_{1}}(t), m^{k_{2}}(t), \ldots\right)\right.$ : for every $k \in K m^{k}(t)$ satisfies $\left.(5)\right\}$-the set of messages at time $t=1, \ldots, \tau$;

- $\mu_{t}: E_{t} \rightarrow M_{t+1}$-the message correspondence at time $t=1, \ldots, \tau-1$, which to given economic environment $e_{t}$ assigns set

- $\mu_{t}\left(e_{t}\right)=\left\{m_{t+1} \in M_{t+1}: m^{k}(t+1)=f_{t}^{k}\left(m_{t}, e_{t}\right)\right.$ for every $\left.k \in K\right\}$, of feasible messages at price vector $p(t+1)$,

- $h_{t}: M_{t} \rightarrow Z_{t}$-the outcome function for $t=1, \ldots, \tau$.

On the basis of the above, the structure $\Gamma_{t}=\left(M_{t+1}, \mu_{t}, h_{t}\right)$, for $t=1, \ldots, \tau-1$, is the mechanism in the sense of Hurwicz.

Proof of Remark 1 The proof goes in the same way as the proof of Theorem 1 except the definitions of the message correspondence and the outcome set. Here, the message correspondence $\mu_{t}$ to every environment at time $t$ (denoted by $e_{t}$ ) assignes the message at time $t$ (denoted by $m_{t}$ ) while the outcome set $Z_{t}$ is of the form (15). On the basis of the above, the structure $\Gamma_{t}=\left(M_{t}, \mu_{t}, h_{t}\right)$ for $t=1, \ldots, \tau$ is the mechanism in the sense of Hurwicz.

\section{Acknowledgements}

I wish to thank Andrzej Malawski, distinguished mathematician, philosopher and economist, who passed away in 2016

for inspired discussions and the idea of that paper.

I am very grateful for reviewers' comments which enabled to significantly improve the paper

\section{Authors' contributions}

AM: conceptualizing the idea. AL: conceptualizing the idea, analysis and writing. Both authors read and approved the final manuscript.

Funding

This work is supported by National Science Centre in Poland, Grant 2014/13/B/HS4/03348.

Availability of data and materials

Not applicable.

\section{Declarations}

Ethics approval and consent to participate

Not applicable.

Consent for publication

Not applicable.

Competing interests

There is none.

Received: 2 July 2020 Revised: 11 March 2021 Accepted: 12 March 2021

Published online: 26 March 2021

References

Abdulkadiroğlu A, SönmezT (2003) School choice: a mechanism design approach. Am Econ Rev 93(3):729-747 
Abdulkadiroğlu A, Pathak PA, Roth AE (2005) The New York city high school match. American Economic Review 95(2):364-367

Adamowicz Z, Zbierski P (1997) Logic of mathematics. Wiley, New York

Aghion P, Howitt P (1992) A Model of Growth through Creative Destruction. Econometrica 60(2):323-351

Aghion P, Howitt P (1998) Endogenous Growth Theory. MIT Press, Cambridge, MA, London

Alchian AA (1950) Uncertainty, evolution and economic theory. J Polit Econ 58:211-222

Almudi I, Fatas-Villafranca F, Jarne G, Sanchez-Choliz J (2019) An evolutionary growth model with banking activity. Metroeconomica. https://doi.org/10.1111/meca.12281

Almudi I, Fatas-Villafranca F, Fernandez-Marquez CM, Potts J, Vazquez FJ (2019a) Absorptive capacity in a two sector neoSchumpeterian model: a new role for innovation policy. Ind Corp Chang. https://doi.org/10.1093/icc/dtz052

Andersen ES (2009) Schumpeter's Evolutionary Economics. Anthem Press, London

Antonioli D, Borghesi S, Mazzanti M (2016) Are regional systems greening the economy? Local spillovers, green innovations and firm's economic performances. Econ Innov New Technol. https://doi.org/10.1080/10438599.2015.1127557

Arrow KJ, Debreu G (1954) Existence of an equilibrium for a competitive economy. Econometrica 22:265-290

Arundel A, Kemp R (2009) Measuring eco-innovation, vol 17. Working paper, UNU-MERIT, Maastricht, pp 1-40

Assenza T, Delli Gatti D, Grazzini J (2015) Emergent dynamics of a macroeconomic agent based model with capital and credit. J Econ Dynam Control 50(1):5-28

Bonnevie B, Ehlers L, Vestergaard M, Kidholm K, Pedersen PH (2006) Doing mini-health technology assessments in hospitals: a new concept of decision support in health care? Int J Technol Assess Health Care 22(3):295-301

Carrillo-Hermosilla J, del Rio P, Könnölä T (2010) Diversity of eco-innovations: Reflections from selected case studies. J Clean Prod 18(10-11):1073-1083

Ciałowicz B, Malawski A (2011) The role of banks in the schumpeterian innovative evolution: an axiomatic set-up. In: Pyka A, Derengowski Fonseca M (eds) Catching up, spillovers and innovation networks in a schumpeterian perspective. Springer, Berlin, Heidelberg, pp 31-58

European Commission (2009) Eco-innovation the key to Europe's future competitiveness. https://ec.europa.eu/envir onment/pubs/pdf/factsheets/ecoinnovation/en.pdf. Accessed 4 Jan 2021

Crespi F, Mazzanti M, Managi S (2016) Environmental Economics and Policy Studies 18:137-141. https://doi.org/10.1007/ s10018-016-0141-X

Dawid H, Harting P, van der Hoog S, Neugart M (2019) Macroeconomics with heterogeneous agent models: fostering transparency, reproducibility and replication. J Evol Econ 29:467-538

Day RH (2007) The mechanisms of economic evolution: completing Schumpeter's theory. In: Hanusch H, Pyka A (eds) Elgar Companion to Neo-Schumpeterian Economics. Edward Elgar, Cheltenham, pp 745-753

Debreu G (1959) Theory of Value. Wiley, New York

Dewatripont M, Maskin E (1995) Credit and Efficiency in Centralized and Decentralized Economies. Rev Econ Stud 62(4):541-555

Dewick P, Maytorena-Sanchez E, Winch G (2019) Regulation and regenerative eco-innovation: the case of extracted materials in the UK. Ecol Econ 160:38-51

Dosi G, Fagiolo G, Roventini A (2010) Schumpeter meeting Keynes. A policy-friendly model of endogenous growth and business cycles. J Econ Dyn Control 34(9):1748-1767

Faucheux S, Nicolaï I (2011) IT for Green and Green IT: a proposed typology of eco-innovation Ecological Economics. Elsevier, New York

Foster J (2011) Evolutionary macroeconomics: a research Agenda. In: Pyka A, Derengowski Fonseca M (eds) Catching up, spillovers and innovation networks in a schumpeterian perspective. Springer, Berlin

Freeman C (1982) The Economics of Industrial Innovations, 2nd edn. Printer, London

Hanusch H, Pyka A (2007) Schumpeter, Joseph Allois (1883-1950). Elgar companion to neo-schumpeterian economics. Edward Elgar, Cheltenham, pp 19-26

Hayek FA (1945) The use of knowledge in society. Am Econ Rev 35:8

Hodgson GM (1993) Economics and evolution: bringing life back into economics. Polity Press, Cambridge

Hurwicz L (1960) Optimality and informational efficiency in resource allocation processes. In: Arrow K, Karlin S, Suppes P (eds.) Mathematical Methods in the Social Sciences. Stanford University Press, Stanford, California.

Hurwicz L (1972) On informationally decentralized systems. In: Radner R, McGuire CB (eds.) Decision and Organization, a volume in honour of Jacob Marschak, pp 297-336.

Hurwicz L (1987) Incentive Aspects of Decentralization. In: Arrow K, Intriligator MD (eds.) Handbook of Mathematical Economics, vol. 3. Amsterdam.

Hurwicz L, Reiter S (2006) Designing economic mechanism. Cambridge University Press, New York

Joller $L$ (2012) Eco-innovation in business models-theoretical considerations. Paper presented at DRUID Academy Conference. Cambridge, UK. https://www.academia.edu/32300911/Eco-innovation_in_business_models_theoretical_ considerations. Accessed 12 Oct 2019

Leal-Millán A, Leal-Rodríguez AL, Albort-Morant G (2017) Green Innovation. In: Carayannis E (ed) Encyclopedia of creativity, invention, innovation and entrepreneurship. Springer, New York

Lipieta A (2010) The Debreu private ownership economy with complementary commodities and prices. Econ Model 27:22-27

Lipieta A (2015) Producers' adjustment trajectories resulting in equilibrium in the economy with linear consumption sets. Central Eur J Econ Modell Econometr 7:187-204

Lipieta A (2018) The role of imitative mechanisms within the economic evolution. Econ Bus Rev 18(4):62-82. https://doi. org/10.18559/ebr.2018.4.4

Lipieta A, Malawski A (2016) Price versus quality competition. Search for Schumpeterian evolution mechanisms. J Evol Econ 1137:1171. https://doi.org/10.1007/s00191-016-0470-8

Malawski A (2005) A Dynamical System Approach to the Arrow-Debreu Theory of General Equilibrium. In: The 9th world multi-conference on systemics, cybernetics and informatics, proceedings 2005, Orlando, Florida, USA, Vol VII, pp 434-439 
Malawski A (2008) distributive justice and schumpeterian innovative evolution - an axiomatic approach in the context of social cohesion. In: Proceedings of the fourth international conference on quality of life improvement through social cohesion. In: Ostasiewicz W (ed) Wrocław University of Economics, pp 80-98

Malawski A (ed) (2013) Innovative economy as the Object of Investigation in Theoretical Economics. Cracow University of Economics Press, London

Malawski A, Woerter M (2006) Diversity structure of the schumpeterian evolution. An axiomatic approach. Arbeitspapiere/Working Papers of the Swiss Institute for Business Cycle Research, No 153, Oct. 2006, Zurich

Malerba F, Orsenigo L (1995) Schumpeterian patterns of innovation. Camb J Econ 19:47-65

Malerba F, Orsenigo L (1997) Technological regimes and sectoral patterns of innovative activities. Ind Corp Chang 6:83-117

Marschak J, Radner R (1971) The economic theory of teams. Yale University Press, New Haven, CN

Mas-Colell A, Whinston MD, Green JR (1995) Microeconomic theory. Oxford University Press, New York

Maskin E, Riley J (1984) Optimal auctions with risk averse buyers. Econometrica 52(6):1473-1518

Maskin E, Qian Y, Xu C (2000) Incentives, information, and organizational form. Review Econ Stud 67(2):359-378

Moore J (2007) General Equilibrium and Welfare Economics. Springer, Berlin-Heidelberg-New York

Mount K, Reiter S (1974) The informational size of message spaces. J Econ Theory 8:161-191

Myerson RB (1979) Incentive compatibility and the bargaining problem. Econometrica 47(1):61-73

Myerson RB (1983) Mechanism design by an informed principal. Econometrica 51(6):1767-1797

Myerson RB (1984) Two-person bargaining problems with incomplete information. Econometrica 52(2):461-487

Nelson R (2016) Behaviour and cognition of economic actors in evolutionary economics. J Evol Econ 26:737-751. https:// doi.org/10.1007/s00191-015-0431-7

Nelson R, Winter S (1982) An evolutionary theory of economic change. Belknap Press of Harvard University Press, Cambridge

Pycia M, Ünver MU (2017) Incentive compatible allocation and exchange of discrete resources. Theor Econ 12(1):287-329

Radner R (1972) Normative theories of organization. In: Radner R, McGuire CB (eds) Decision and Organization. North Holland, pp 189-216.

Rennings K (2000) Redefining innovation-eco-innovation research and the contribution from ecological economies.

Ecol Econ 32(3):319-332. https://doi.org/10.1016/S0921-8009(99)00112-3

Romer D (2012) Advanced macroeconomics, 4th edn. McGraw-Hill, New York

Roth AE, Sönmez T, Ünver MU (2004) Kidney exchange. Quart J Econ 119(2):457-488

Schumpeter JA (1912) Die Theorie der wirtschaftlichen Entwicklung. Duncker \& Humblot, Leipzig

Schumpeter JA (1934) The theory of economic development. Harvard University Press, Cambridge, MA

Schumpeter JA (1950) Capitalism, socialism and democracy, 3rd edn. Harper, New York

Schumpeter JA (1964) Business cycles: a theoretical, historical, and statistical analysis of the capitalist process. McGrawHill, New York, London

Shionoya Y (2015) Schumpeter and evolution: an ontological exploration. http://www.lib.hit-u.ac.jp/service/tenji/amjas/ Shionoya18.pdf. Accessed 29 Dec 2015.

Simon HA (1947) Administrative Behavior. Macmillan, London

Simon HA (1955) A behavioural model of rational choice. Quart J Econ 69:99-118

Simon HA (1957) Models of Man. Wiley, New York

Sönmez T, Ünver MU (2011) Matching, allocation, and exchange of discrete resources. In: Bisin A, Benhabib J, Jackson M (eds) Handbook of Social Economics. Springer, Berlin, pp 781-852

Szutowski D, Szulczewska-Remi A, Ratajczak P (2017) The efficiency of eco-innovations. Systematic literature studies. Econ Environ Stud 17(2):205-219

Witt U (2017) The evolution of consumption and its welfare effects. Journal of Evolutionary Economics 27:273-293. https://doi.org/10.1007/s00191-016-0459-3

\section{Publisher's Note}

Springer Nature remains neutral with regard to jurisdictional claims in published maps and institutional affiliations.

\section{Submit your manuscript to a SpringerOpen ${ }^{\circ}$ journal and benefit from:}

- Convenient online submission

- Rigorous peer review

- Open access: articles freely available online

- High visibility within the field

- Retaining the copyright to your article

Submit your next manuscript at $\boldsymbol{\nabla}$ springeropen.com 